\title{
Article \\ COMP and TSP-4: Functional Roles in Articular Cartilage and Relevance in Osteoarthritis
}

\author{
Kathrin Maly ${ }^{1}$, Enrique Andres Sastre ${ }^{2}$ (D), Eric Farrell ${ }^{2}$, Andrea Meurer ${ }^{1}$ and Frank Zaucke ${ }^{1, *(D)}$ \\ 1 Research Unit for Osteoarthritis, Department of Orthopaedics (Friedrichsheim), \\ University Hospital Frankfurt, Goethe University, Marienburgstraße 2, 60528 Frankfurt/Main, Germany; \\ kathrin_maly@gmx.at (K.M.); andrea.meurer@kgu.de (A.M.) \\ 2 Department of Oral and Maxillofacial Surgery, Erasmus MC, University Medical Centre Rotterdam, \\ Wytemaweg 80, 3015 CN Rotterdam, The Netherlands; enadestre2@gmail.com (E.A.S.); \\ e.farrell@erasmusmc.nl (E.F.) \\ * Correspondence: frank.zaucke@kgu.de
}

Citation: Maly, K.; Andres Sastre, E.; Farrell, E.; Meurer, A.; Zaucke, F. COMP and TSP-4: Functional Roles in Articular Cartilage and Relevance in Osteoarthritis. Int. J. Mol. Sci. 2021 22, 2242. https://doi.org/10.3390/ ijms22052242

Academic Editor: Chih-Hsin Tang

Received: 28 January 2021

Accepted: 20 February 2021

Published: 24 February 2021

Publisher's Note: MDPI stays neutral with regard to jurisdictional claims in published maps and institutional affiliations.

Copyright: (c) 2021 by the authors. Licensee MDPI, Basel, Switzerland. This article is an open access article distributed under the terms and conditions of the Creative Commons Attribution (CC BY) license (https:// creativecommons.org/licenses/by/ $4.0 /)$.

\begin{abstract}
Osteoarthritis (OA) is a slow-progressing joint disease, leading to the degradation and remodeling of the cartilage extracellular matrix (ECM). The usually quiescent chondrocytes become reactivated and accumulate in cell clusters, become hypertrophic, and intensively produce not only degrading enzymes, but also ECM proteins, like the cartilage oligomeric matrix protein (COMP) and thrombospondin-4 (TSP-4). To date, the functional roles of these newly synthesized proteins in articular cartilage are still elusive. Therefore, we analyzed the involvement of both proteins in OA specific processes in in vitro studies, using porcine chondrocytes, isolated from femoral condyles. The effect of COMP and TSP-4 on chondrocyte migration was investigated in transwell assays and their potential to modulate the chondrocyte phenotype, protein synthesis and matrix formation by immunofluorescence staining and immunoblot. Our results demonstrate that COMP could attract chondrocytes and may contribute to a repopulation of damaged cartilage areas, while TSP-4 did not affect this process. In contrast, both proteins similarly promoted the synthesis and matrix formation of collagen II, IX, XII and proteoglycans, but inhibited that of collagen I and X, resulting in a stabilized chondrocyte phenotype. These data suggest that COMP and TSP-4 activate mechanisms to protect and repair the ECM in articular cartilage.
\end{abstract}

Keywords: COMP; TSP-4; extracellular matrix; articular cartilage; osteoarthritis

\section{Introduction}

Articular cartilage consists of an extracellular matrix (ECM) with a unique composition and architecture, providing the biomechanical properties for frictionless motion [1-3]. The tissue is organized in four zones: the superficial zone at the top, the transitional zone, the deep zone and the calcified zone [1]. Also, the area around the chondrocytes is subdivided into a pericellular matrix directly surrounding the chondrocytes, a territorial matrix, surrounding the pericellular matrix and the interterritorial matrix, the area between the territorial matrices. The main components of the ECM are proteoglycans and collagens, responsible for elasticity and stiffness, respectively [1]. The predominant collagen II forms fibrils with collagen XI as a core and collagen IX on its surface [4-6]. The distribution of different collagen types depends on the zonal localization. Thinner collagen fibrils are associated with collagen IX [5,6], while thicker fibrils are not [6,7]. Fibrils in the superficial zone are also associated with collagen XII [8]. Collagen IX and XII both belong to the fibril-associated collagens with interrupted triple helices (FACIT). They are structurally similar [9] but, in contrast to collagen IX, collagen XII is noncovalently linked to fibrillar collagens [10]. Collagen $X$ is restricted to the calcified zone and represents a transitional area, linking the articular cartilage to the bone [11-14]. To a minor extent, the ECM also contains noncollagenous proteins [2], e.g., the cartilage oligomeric matrix protein 
(COMP), which promotes collagen secretion and assembly as well as ECM stability $[15,16]$. Chondrocytes are surrounded by a dense ECM and remain quiescent in mature cartilage, mediating ECM homeostasis in a low turnover state [17]. In osteoarthritis (OA), alterations at the cellular and molecular levels cause a continuous degradation of the ECM, leading to joint failure and pain $[18,19]$. Chondrocytes produce degrading proteases and are reactivated to synthesize ECM proteins, resulting in ECM remodeling [15,18,20-22]. The cause of chondrocyte reactivation is not completely understood, but might be regulated by cell-matrix interactions. Growth factors like TGF- $\beta 1$ [23-26], which are commonly stored in the ECM and released under certain circumstances, play an important role by regulating processes like cell proliferation and differentiation $[27,28]$, in particular via the Smad and Erk signaling pathways [24,29-32]. The level of activated TGF- $\beta 1$ is increased in the synovial fluid of OA patients [33], suggesting enhanced interaction with chondrocytes in cases of disease. During OA progression, the phenotype of chondrocytes becomes unstable [34], resulting in the loss of chondrogenic markers (collagen II, collagen IX and COMP) [35] and the synthesis of ECM components that are usually not expressed in articular cartilage, like collagen I and collagen X [36-38]. The ECM protein COMP is a target of degradation in early OA, but is also re-expressed in later stages [15]. In contrast, its close family member, thrombospondin-4 (TSP-4), is hardly detectable in healthy cartilage, but its expression increases dramatically in OA cartilage and correlates with disease severity [39]. Both proteins have similar structures and binding partners [40-46], suggesting similar or additive roles in articular cartilage. It has also been reported that COMP binds TGF- $\beta 1$, thereby promoting its transcriptional capacity [47], while this has not yet been shown for TSP-4. The re-expression of COMP and the new synthesis of TSP-4 in OA was interpreted as an attempt to restore the integrity of the cartilage ECM $[15,39]$. However, the effect of these ECM proteins on the chondrocyte phenotype and behavior, as well as their contribution to OA relevant processes and ECM repair, have not yet been investigated in detail. Therefore, the present study focuses on the potential of COMP and TSP-4 to promote repopulation of damaged cartilage areas by attracting chondrocytes, stabilizing their phenotype as well as inducing the synthesis and deposition of collagens and proteoglycans. The obtained data will contribute to a better understanding of the functional role of COMP and TSP-4 in articular cartilage, and might help to improve and develop effective therapeutic applications.

\section{Results}

2.1. COMP and TSP-4 Are Differentially Distributed in Human Healthy and OA Knee Articular Cartilage

Healthy and osteoarthritic cartilage tissue was paraffin-embedded and sections were stained for COMP and TSP-4 (Figure 1a,b). In healthy cartilage, COMP was ubiquitously and uniformly expressed throughout all layers. In the deep zone, the staining was mainly found in the interterritorial matrix. In addition, faint intracellular staining was observed. In OA cartilage, the staining in the superficial zone became weaker, and interterritorial COMP seemed primarily to be degraded. Instead, a pronounced intracellular staining of COMP was detected in the superficial zone, suggesting a re-expression of the protein. TSP-4 was hardly detectable in healthy cartilage, but could be detected in high levels in OA cartilage. While COMP was predominantly re-expressed at the cartilage surface, increased expression of TSP-4 was found mainly in the middle and deeper zone of articular cartilage.

In order to get a deeper insight into the amounts and structural integrity of COMP and TSP-4 in OA cartilage, total protein extracts from areas with different degradation stages were generated (grade 1 (G1): smooth surface and no fissures; grade 2 (G2): superficial discontinuities and fissures and grade 3/4 (G3/4): deep fissures and visibility of the subchondral bone). An immunoblot analysis of these extracts (Figure 1c) revealed that in the tissue TSP-4 was mainly present as a full-length pentameric protein, while COMP already showed signs of degradation, indicated by bands of lower molecular weight. Further, the total amount of COMP and TSP-4 was evaluated and the fold change in G2 and G3/4 samples related to G1 (set as 1) was calculated. The total amount of both proteins 
increased with disease severity. Interestingly, the increase in protein levels was much more pronounced for TSP-4 than for COMP. This increase was only significant for TSP-4 (Figure 1d).

(a)

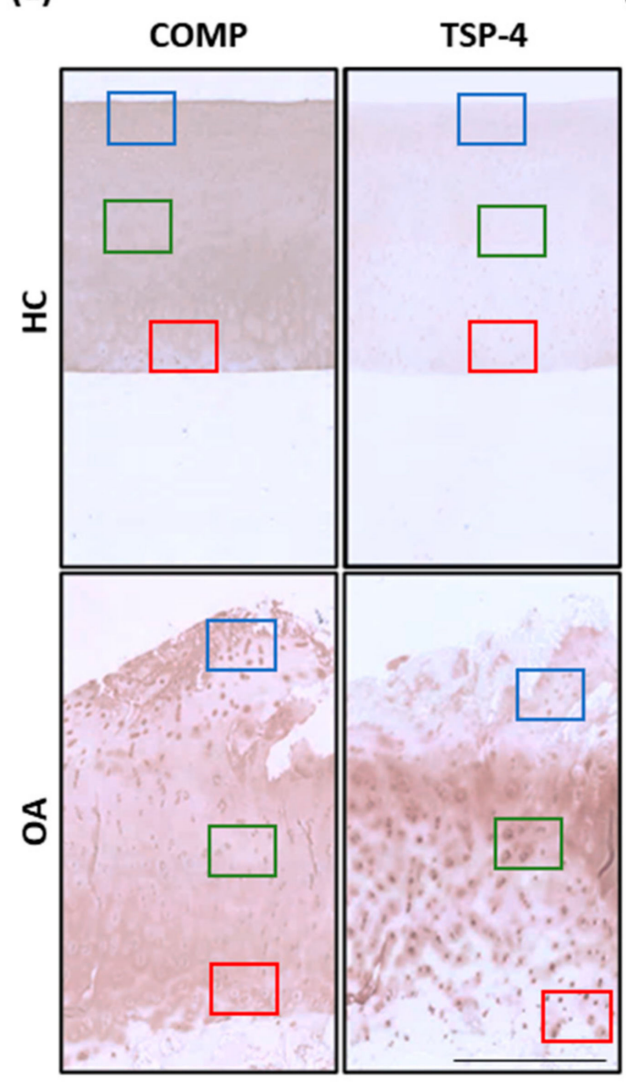

(b)

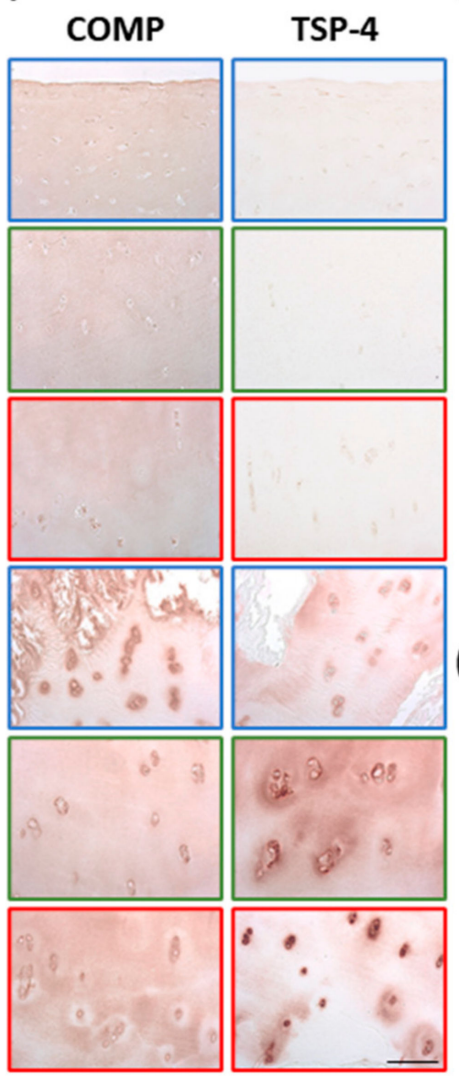

(c)
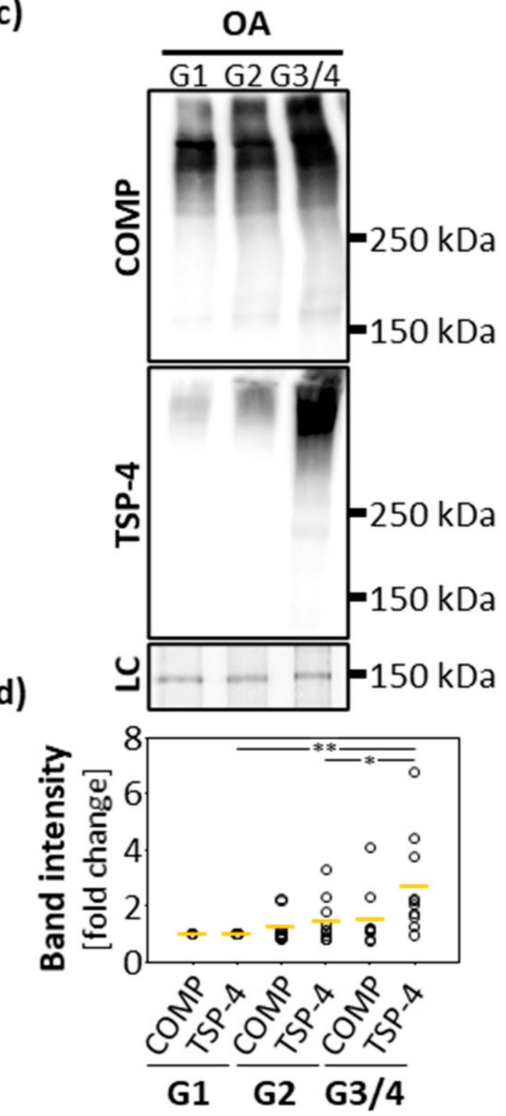

Figure 1. Localization and expression of COMP and TSP-4 in human articular cartilage. (a) Articular cartilage sections from femoral condyles from healthy controls (HC) and OA patients (OA) were stained with COMP and TSP-4 specific antibodies. Scale bar $=1 \mathrm{~mm}$. (b) Magnifications of tissue areas indicated with the boxes in (a). Scale bar $=100 \mu \mathrm{m}$. (c) Total COMP and TSP-4 content was investigated via immunoblots, with proteins extracted from OA cartilage areas showing different degeneration grades (grade 1 (G1), grade 2 (G2) and grade 3/4). PageBlue ${ }^{\mathrm{TM}}$ staining was used as loading control (LC). Representative immunoblots from 10 different donors are shown. (d) Quantification and statistical analyses of the immunoblots. Values are represented as scatter plots with indicated mean as fold changes to G1 (set as 1). The significance of the increase in COMP and TSP-4 is indicated $\left(p<0.05^{*}, p<0.01^{* *}\right)$.

\subsection{COMP but Not TSP-4 Promotes Chondrocyte Migration and Attachment}

In order to analyze the function of COMP and TSP-4 during OA progression, recombinant proteins were expressed and purified for downstream in vitro assays (Figure 2a). Both recombinant proteins could be produced in sufficient amounts and showed a high structural similarity to the naturally occurring proteins in OA cartilage (Figure 1c). 
(a)

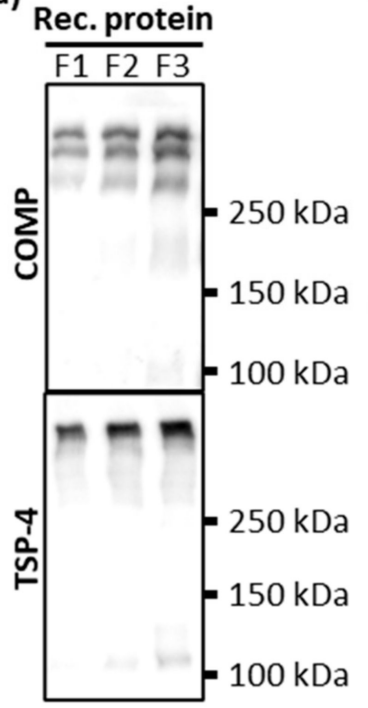

(e)

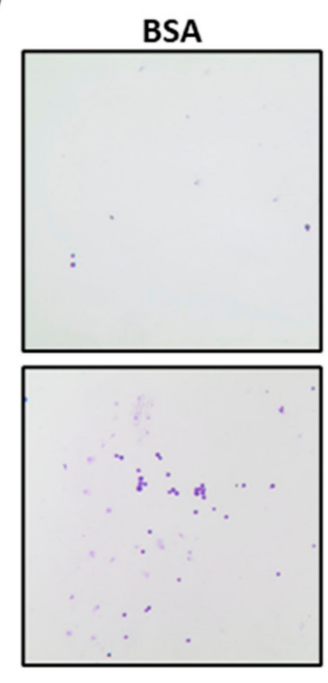

COMP (b)

(c)

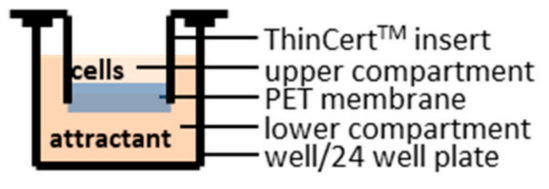

(d)

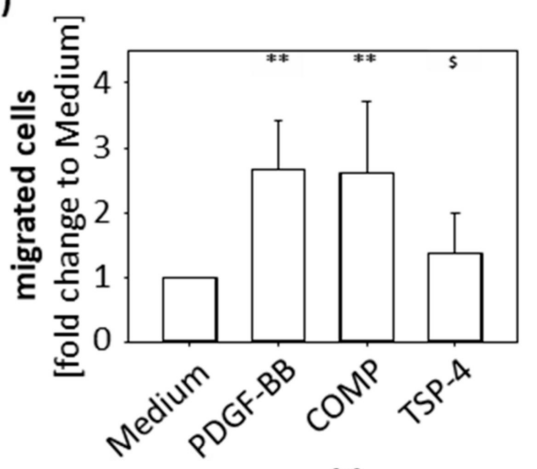

(f)
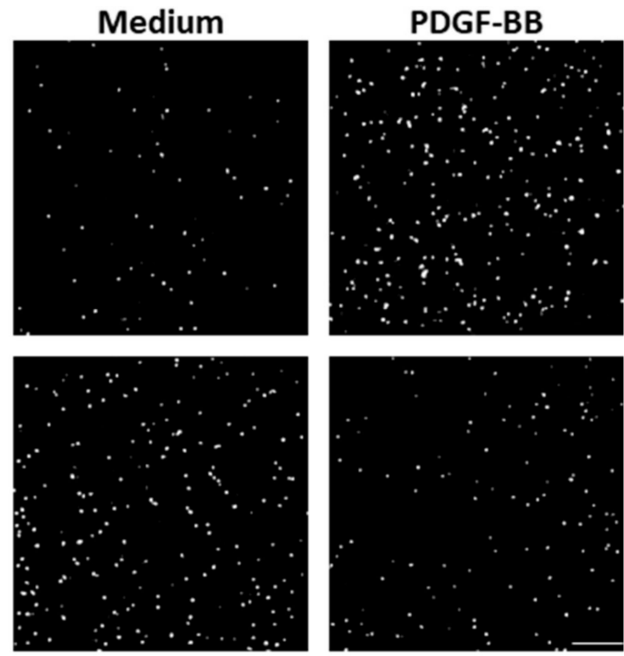

COMP

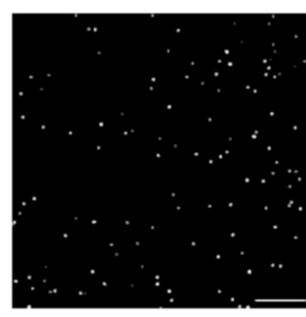

TSP-4
Fibronectin
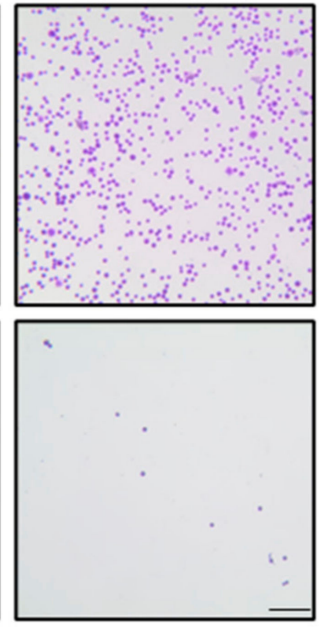

TSP-4

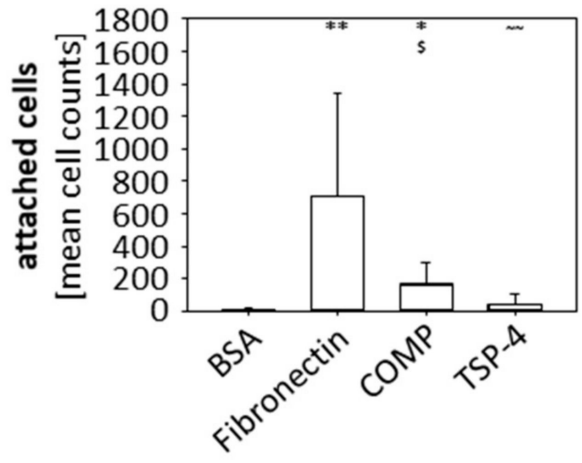

Figure 2. Chondrocyte migration and attachment to COMP and TSP-4. (a) Recombinant (rec) COMP and TSP-4 were eluted from the columns in several steps and every protein fraction $(\mathrm{F})$ analyzed by immunoblot. (b) Schematic illustration of the transwell system. Porcine chondrocytes were added to the upper compartment and allowed to migrate towards COMP $(10 \mu \mathrm{g} / \mathrm{mL})$ or TSP-4 $(10 \mu \mathrm{g} / \mathrm{mL})$ for $10 \mathrm{~h}$. (c) Representative images of migrated chondrocytes stained with DAPI. (d) Migrated cells were counted and cell numbers statistically evaluated. Each bar shows the mean + SD and significance (to medium: $p<0.01^{* *}$ and to PDGF-BB: $p<0.05$ \$) was analyzed. (e) Representative images of attached chondrocytes stained with crystal-violet. (f) Attached cells were counted and cell numbers statistically evaluated. Each bar shows the mean + SD and significance (to BSA $p<0.05^{*}, p<0.01^{* *}$, to fibronectin $p<0.05 \$$ and COMP $p<0.01 \sim \sim$ ) was analyzed. The standard medium was used as a negative and PDGF-BB $(10 \mathrm{ng} / \mathrm{mL})$ as a positive control for the migration assay. BSA $(100 \mathrm{mg} / \mathrm{mL})$ was used as a negative control and fibronectin $(10 \mu \mathrm{g} / \mathrm{mL})$ as a positive control for cell attachment. $(n=4-5)$; scale bar $=100 \mu \mathrm{m}$.

The immunohistochemical staining showed that the localization of COMP and TSP-4 differs between healthy and diseased cartilage; while COMP is re-expressed in superficial layers, TSP-4 is predominantly expressed in the middle and deep zones in OA conditions. To gain knowledge about the capacity of COMP to attract chondrocytes and contribute to their migration into the areas of damage to support repair undertakings, transwell mi- 
gration assays were performed. As attractants, COMP $(10 \mu \mathrm{g} / \mathrm{mL})$ and TSP-4 $(10 \mu \mathrm{g} / \mathrm{mL})$ were added to the lower compartment, and porcine chondrocytes in the upper compartment were allowed to migrate for $10 \mathrm{~h}$ (Figure $2 \mathrm{~b})$. PDGF-BB $(10 \mathrm{ng} / \mathrm{mL})$ was used as a positive and standard medium as a negative control. Both COMP $(p=0.014)$ and PDGF-BB $(p=0.012)$ attracted chondrocytes compared to the negative control (Figure $2 \mathrm{c}, \mathrm{d})$. The number of cells migrating towards TSP-4 was similar to the negative control. (Figure 2c,d).

To determine whether COMP could also facilitate the attachment and anchorage of the attracted chondrocytes, wells of a 96-well plate were coated with $10 \mu \mathrm{g} / \mathrm{mL}$ COMP and also TSP-4; $10 \mu \mathrm{g} / \mathrm{mL}$ fibronectin was used as a positive control and $100 \mathrm{mg} / \mathrm{mL}$ BSA as a negative control. Chondrocytes were incubated in coated wells for $1 \mathrm{~h}$, the attached cells were stained with crystal-violet and analyzed by light microscopy (Figure 2e,f). Chondrocytes attached to fibronectin $(p=0.003)$ and COMP $(p=0.012)$ but not to TSP-4 $(p=0.18)$. Also, an increased attachment for COMP compared to TSP-4 $(p=0.007)$ was observed. These data demonstrated that COMP but not TSP-4 has the potential to attract chondrocytes and facilitate their attachment.

\subsection{Both COMP and TSP-4 Modulate Collagen and Proteoglycan Synthesis}

To determine whether COMP and TSP-4 could further stimulate chondrocytes to synthesize collagens and proteoglycans to rebuild the ECM in damaged areas and contribute to ECM remodeling in lower cartilage areas, chondrocytes were stimulated with COMP $(10 \mu \mathrm{g} / \mathrm{mL})$, TSP-4 $(10 \mu \mathrm{g} / \mathrm{mL})$, TGF- $\beta 1(0.5 \mathrm{ng} / \mathrm{mL})$ or in combination of TGF- $\beta 1$ with COMP or TSP-4 for seven days. To ensure that the chondrocyte phenotype in monolayer culture remained stable, the stimulation experiments were stopped after three more days. COMP and TSP-4 directly interact with TGF- $\beta 1$ (Appendix A, Figure A1), and COMP is further known to modulate the transcriptional activity of TGF- $\beta 1$ [47]. Therefore, TGF- $\beta 1$ alone was used as an inducer of collagen synthesis (positive control), while the combination with COMP and TSP- 4 was used to observe their potential to modulate TGF- $\beta 1$-induced effects. As a negative control, chondrocytes were cultured in standard medium. Matrixassociated collagens were detected by immunofluorescence staining, and matrix-associated proteoglycans were stained with Safranin-O (Figure 3a).

COMP and TSP-4 stimulation resulted in an increased staining intensity of matrixassociated collagen II, IX, XII and proteoglycan, while no effect on collagen I and a slight decrease of collagen $X$ deposition could be observed. TGF- $\beta 1$ enhanced the matrix formation of collagen I, II, XII and proteoglycan while reducing collagen IX levels and not affecting collagen $X$. Investigating the effect of COMP and TSP-4 on TGF- $\beta 1$ induced matrix formation showed a decrease of collagen I, X and XII levels, as well as an increase of collagen II and proteoglycan. TGF- $\beta 1$ associated collagen IX reduction could not be reversed by COMP or TSP-4. By investigating the effect of TGF- $\beta 1$ on the expression of COMP and TSP-4, we showed that TGF- $\beta 1$ only induces the synthesis of COMP, but not of TSP-4 (Appendix B, Figure A2).

Collagens that are not integrated into the matrix remain soluble and can be detected in the cell culture supernatant. Therefore, the amount of different collagen types was analyzed by immunoblot assays (Figure $3 \mathrm{~b}$ ). Soluble collagen IX could only be detected in supernatants of cells treated with COMP, either alone or in combination with TGF- $\beta 1$. This result showed that COMP contributes to the synthesis of collagen IX, even though its deposition into the matrix seems not to be significantly increased. Elevated amounts of soluble collagen I and XII could be observed only in TGF- $\beta 1$ stimulated cells; this upregulation parallels the increase of the respective proteins in the matrix. Interestingly, the amount of the same proteins in the supernatant could be reduced by the addition of COMP or TSP-4. The signals for collagen X and collagen II in the supernatant were either very weak or absent altogether, indicating that these proteins are quantitatively incorporated into the cell-associated matrix. 
(a)

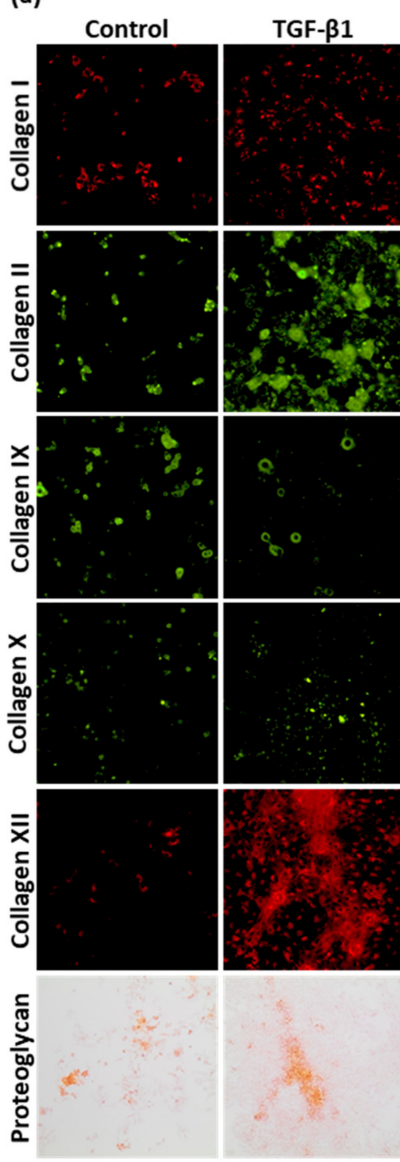

(b)
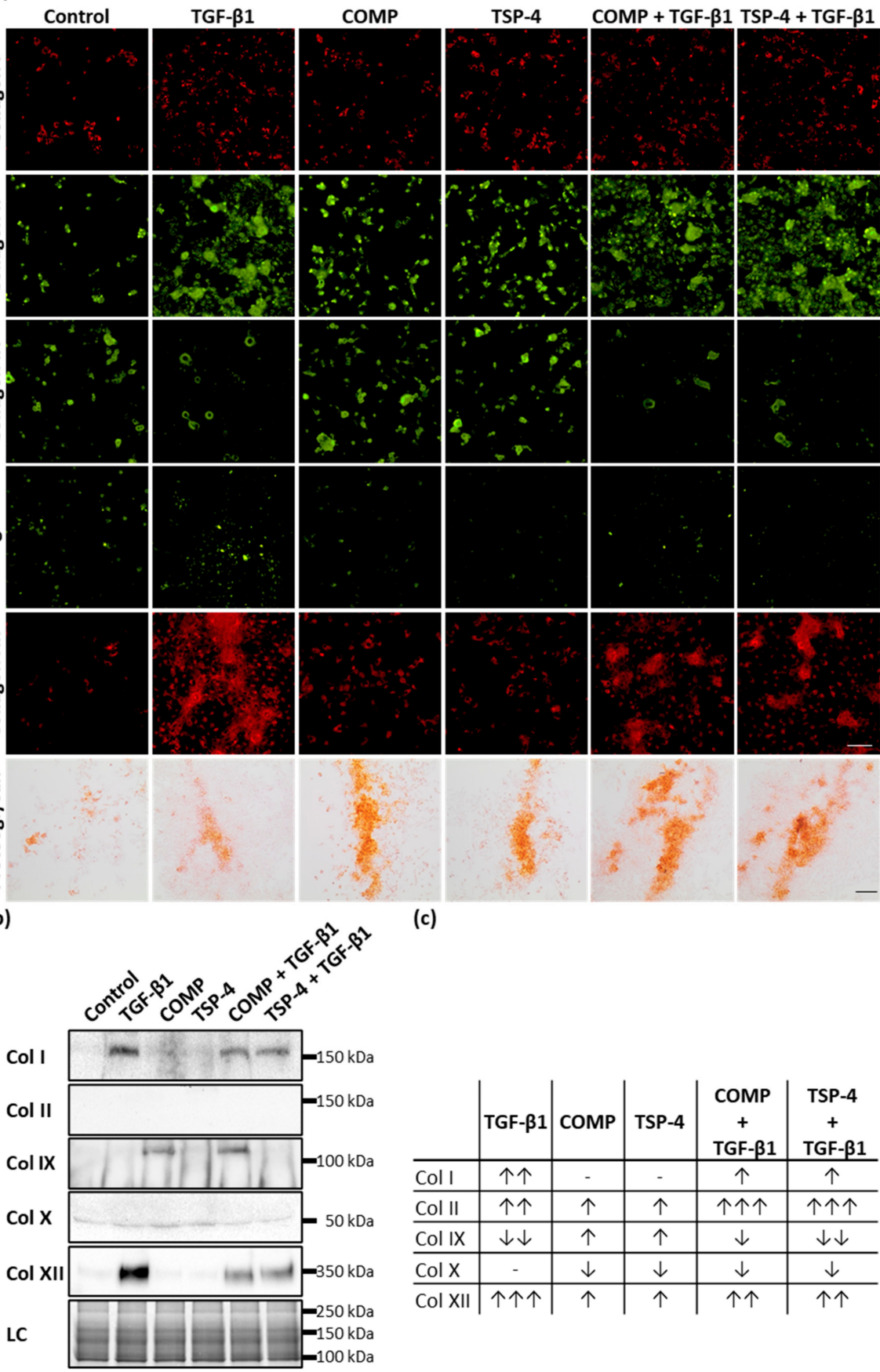

(c)
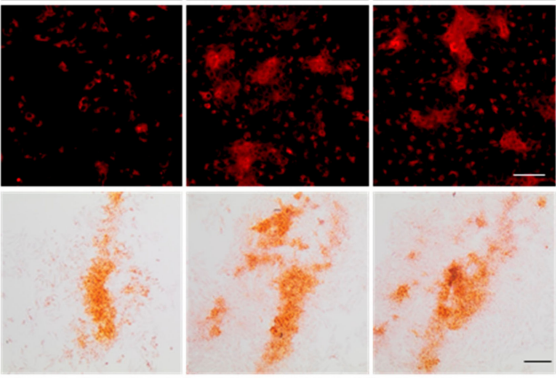

\begin{tabular}{l|c|c|c|c|c} 
& TGF- $\beta 1$ & COMP & TSP-4 & $\begin{array}{c}\text { COMP } \\
+ \\
\text { TGF- } \beta 1\end{array}$ & $\begin{array}{c}\text { TSP-4 } \\
+ \\
\text { TGF- } \beta 1\end{array}$ \\
\hline Col I & $\uparrow \uparrow$ & - & - & $\uparrow$ & $\uparrow$ \\
\hline Col II & $\uparrow \uparrow$ & $\uparrow$ & $\uparrow$ & $\uparrow \uparrow \uparrow$ & $\uparrow \uparrow \uparrow$ \\
\hline Col IX & $\downarrow \downarrow$ & $\uparrow$ & $\uparrow$ & $\downarrow$ & $\downarrow \downarrow$ \\
\hline Col X & - & $\downarrow$ & $\downarrow$ & $\downarrow$ & $\downarrow$ \\
\hline Col XII & $\uparrow \uparrow \uparrow$ & $\uparrow$ & $\uparrow$ & $\uparrow \uparrow$ & $\uparrow \uparrow$
\end{tabular}

Figure 3. The effect of COMP and TSP-4 on collagen and proteoglycan production and deposition. Chondrocytes were stimulated with COMP $(10 \mu \mathrm{g} / \mathrm{mL})$, TSP-4 $(10 \mu \mathrm{g} / \mathrm{mL})$ alone or in combination with TGF- $\beta 1(0.5 \mathrm{ng} / \mathrm{mL})$ for seven days. (a) Immunofluorescence staining of collagen (Col) I, II, IX, X and XII as well as Safranin-O staining of proteoglycans at day 10. (b) Immunoblot assays of chondrocyte supernatants at day 10. Roti ${ }^{\circledR}$ blue staining of proteins was used as a loading control (LC). (c) Table summarizing the effect of COMP, TSP-4 and TGF- $\beta 1$ on the total amount of different collagen types (matrix-associated and soluble). The amount of matrix-associated collagens was visually scored from IF staining and combined with band intensities for soluble proteins derived from immunoblots. The number of arrows indicates a strong, moderate or mild effect compared to the control. The direction of the arrows indicates an increase $(\uparrow)$ or decrease $(\downarrow)$ compared to control. No changes are indicated by a minus. The number of arrows indicates strong (three arrows), moderate (two arrows) or mild (one arrow) changes compared to control. (Immunofluorescence staining, $n=3$; immunoblot $n \geq 2$ per group); unstimulated cells were used as a control; scale bar (collagens) $=100 \mu \mathrm{m}$; and (proteoglycans) $=200 \mu \mathrm{m}$. 
Total levels of collagens (matrix-associated and soluble), detected by immunofluorescence staining and immunoblots (Figure $3 \mathrm{c}$ ), showed that COMP and TSP-4 stimulation increased the total level of collagen II, IX and XII, and decreased that of collagen X. TGF- $\beta 1$ increased the expression of collagen I, II and XII while reducing that of collagen IX. These effects on collagen I and XII were weakened by the addition of COMP and TSP-4, while the increase of collagen II expression was further enhanced.

\subsection{COMP and TSP-4 Do Not Affect Proliferation but Suppress Dedifferentiation of Chondrocytes}

Reactivated chondrocytes in OA proliferate and dedifferentiate to collagen I producing cells. COMP and TSP-4 affect collagen II matrix deposition and suppress TGF- $\beta 1$-induced collagen I expression. The primary aim of the following experiments was not to study the dedifferentiation process itself, but to determine whether COMP and TSP-4 could directly or indirectly modulate this process. Chondrocytes were stained as described in Section 2.3 and studied in more detail by evaluating their proliferation and number of total, as well as the ratio, of collagen I and collagen II positive cells. These experiments were repeated three times with different batches of freshly isolated chondrocytes.

TGF- $\beta 1$ served as an inducer of chondrocyte proliferation. COMP $(p=0.99)$ and TSP-4 ( $p=0.86)$ alone had no effect on cell proliferation, and cell numbers were comparable to the untreated control (Figure $4 \mathrm{a}, \mathrm{b})$ after 10 days. TGF- $\beta 1(p=0.003)$ alone and in combination with COMP $(p=0.002)$ or TSP-4 $(p<0.001)$ resulted in an increased cell number. The dual treatments with TGF- $\beta 1$ also increased the cell numbers compared to the equivalent single treatments with COMP $(p=0.013)$ and TSP-4 $(p=0.023)$. These data show that COMP and TSP-4 do not affect cell proliferation, either directly or by modulating the TGF- $\beta 1$ induced proliferation.

The percentage of cells expressing collagen I and collagen II, respectively, was investigated by immunofluorescence double staining (Figure 4c). Collagen I and collagen II expressing cells were counted and the percentage of collagen expressing cells was calculated (Figure $4 \mathrm{~d}$ ). The percentage of collagen I and collagen II expressing cells was comparable between the control $(p=0.21)$ and TGF- $\beta 1(p=0.22)$ treated cultures. For all other treatments, stimulation with COMP $(p=0.003)$, TSP-4 $(p=0.03)$ or in combination with TGF- $\beta 1$ (COMP: $p=0.05$; TSP-4: $p=0.02$ ) resulted in a shift towards collagen II producing cells. The percentage of unstained cells was comparable between groups, ranging from 3 to $11 \%$. Furthermore, the number of collagen I producing cells was lower in cultures treated with COMP $(p=0.025)$ and the costimulations of TGF- $\beta 1$ with COMP $(p=0.007)$ and TSP-4 $(p=0.004)$. The stimulation with TSP-4 $(p=0.056)$ showed a tendency of a reduced number of collagen I positive cells. The opposite was observed for collagen II producing cells, whose numbers increased in cultures treated with COMP $(p=0.033)$, TSP-4 $(p=0.042)$ and in the combination of TGF- $\beta 1$ with COMP $(p=0.034)$ and TSP-4 $(p=0.010)$.

These results show that COMP and TSP-4 are able to suppress chondrocyte dedifferentiation in monolayer culture.

\subsection{COMP and TSP-4 Induce the Phosphorylation of Erk1/2 While Not Affecting the Smad Pathways}

COMP and TSP-4 participate in cartilage maintenance and repair by stabilizing the chondrocyte phenotype and inducing the synthesis of important ECM components. To unravel potential signaling pathways involved, the phosphorylation of Erk and Smad proteins was investigated after stimulation with COMP and TSP-4, respectively.

Chondrocytes were treated with $10 \mu \mathrm{g} / \mathrm{mL}$ COMP or TSP- 4 for $30 \mathrm{~min}$ and phosphorylated Erk1/2, Smad2 and Smad1/5/9 detected by immunoblot analyses. Both COMP and TSP-4 induced the phosphorylation of Erk1/2 (Figure 5a). Even though the treatment with COMP and TSP-4 seemed to slightly increase the level of total Erk1/2, the increase in phosphorylation was much more pronounced. None of the proteins affected the phosphorylation of Smad2 or Smad1/5/9 (Figure 5b). 
(a)

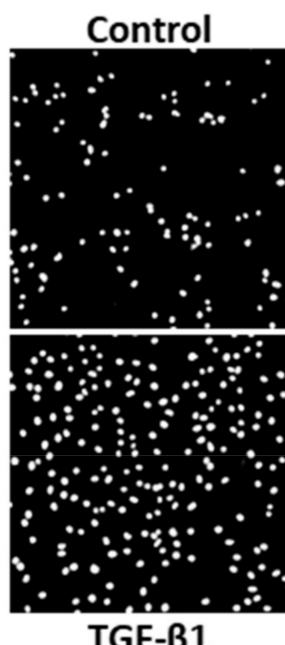

TGF- $\beta 1$

(c)

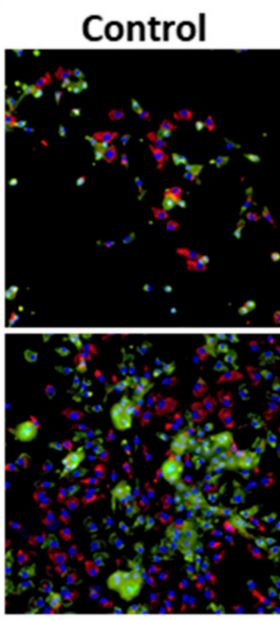

TGF- $\beta 1$
COMP

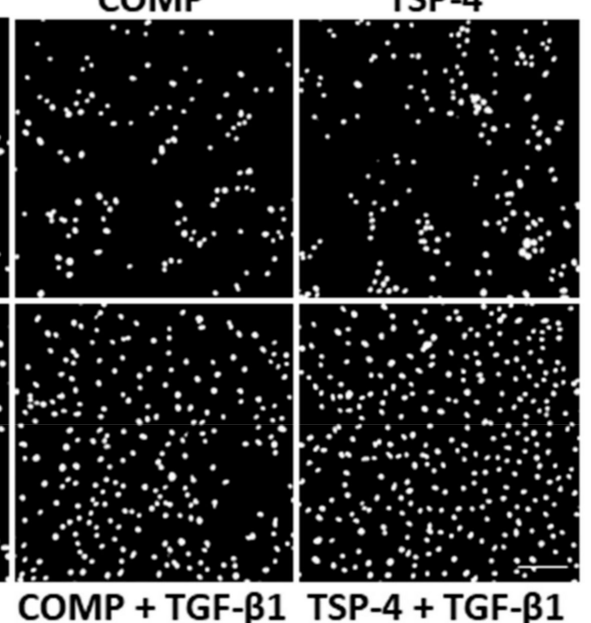

(b)

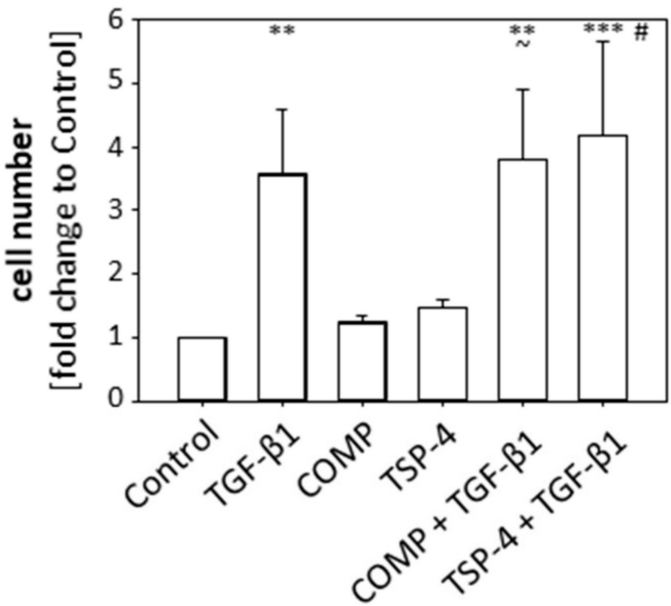

(d)

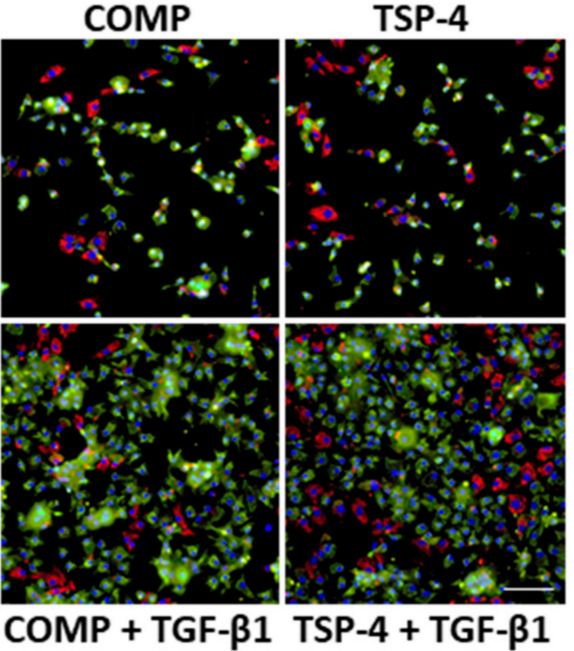

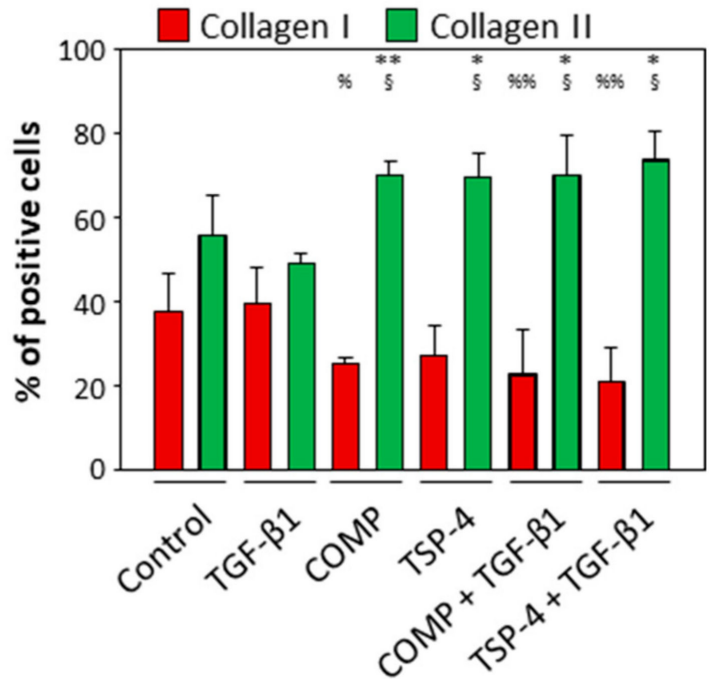

Figure 4. Effect of COMP and TSP-4 on chondrocyte proliferation and dedifferentiation. Chondrocytes were stimulated with COMP $(10 \mu \mathrm{g} / \mathrm{mL})$ or TSP-4 $(10 \mu \mathrm{g} / \mathrm{mL})$ for seven days. (a) Nuclei were DAPI stained at day 10. (b) The fold changes of the counted nuclei are represented and each bar shows the mean + SD. The significant differences between the control and all other conditions were calculated. Differences between COMP, TGF- $\beta 1$ and COMP + TGF- $\beta 1$ as well as TSP- 4 , TGF- $\beta 1$ and TSP-4 + TGF- $\beta 1$ were calculated. Differences to the control are indicated by an asterisk *, to COMP by waves $\sim$ and to TSP-4 by rhombus \#, as well as significance indicated by $p \leq 0.05 \# \sim ; p \leq 0.01^{* *} ; p \leq 0.001^{* * *}$. (c) Immunofluorescence staining of collagen I (red), collagen II (green) and nuclei (blue) at day 10. (d) Percentages of chondrocytes expressing collagen I and II are represented and each bar shows the mean + SD. The significant difference between collagen I and collagen II positive cells was calculated and significance indicated as $p \leq 0.05^{*} ; p \leq 0.01^{* *}$. Differences of collagen I and collagen II positive cells to the control were calculated and significance indicated as $p \leq 0.05 \%$ or $\S ; p \leq 0.01 \% \%$, respectively. TGF- $\beta 1$ $(0.5 \mathrm{ng} / \mathrm{mL})$ served as an inducer of proliferation and collagen synthesis and unstimulated cells as a control. $(n=3)$; scale bar $=100 \mu \mathrm{m}$.

\subsection{COMP and TSP-4 Can Modulate TGF- $\beta 1$ Induced Erk1/2 Signaling}

The effect of TGF- $\beta 1$ on matrix formation was modulated by the simultaneous addition of COMP and TSP-4, respectively. Therefore, the capacity of COMP and TSP-4 to modulate TGF- $\beta 1$-induced Erk signaling was investigated. The phosphorylation of Erk1/2 
was investigated $30 \mathrm{~min}$ after stimulation with $10 \mu \mathrm{g} / \mathrm{mL}$ COMP or TSP-4 and different concentrations of TGF- $\beta 1(0.1 ; 0.25 ; 0.5 ; 1$ and $10 \mathrm{ng} / \mathrm{mL})$. Maximal Erk1/2 phosphorylation was detected after treatment with $0.25 \mathrm{ng} / \mathrm{mL}$ TGF- $\beta 1$ (Figure 6a). The additional stimulation with TSP-4 shifted this phosphorylation maximum to a TGF- $\beta 1$ concentration of $0.5 \mathrm{ng} / \mathrm{mL}$ (Figure $6 \mathrm{c}$ ). The most pronounced Erk1/2 phosphorylation with simultaneous COMP treatment was found at $0.1 \mathrm{ng} / \mathrm{mL}$ TGF- $\beta 1$, and continuously decreased with increasing TGF- $\beta 1$ concentrations (Figure $6 \mathrm{~b}$ ). The phosphorylation maximum at $0.1 \mathrm{ng} / \mathrm{mL}$ TGF- $\beta 1$ was weaker than that of COMP alone. These results show that TSP-4 attenuates TGF- $\beta 1$ induced Erk $1 / 2$ signaling, in contrast to COMP, whose capacity to induce Erk1/2 phosphorylation is suppressed by TGF- $\beta 1$.

(a)

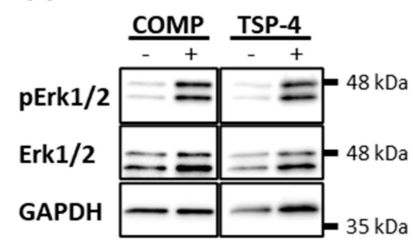

(b)

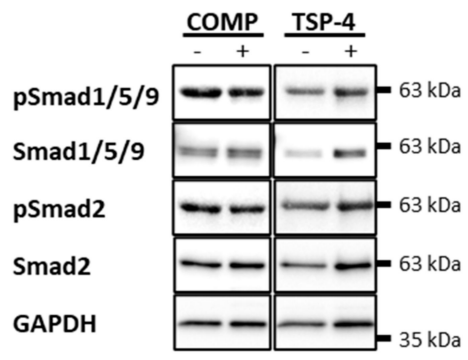

Figure 5. Erk and Smad phosphorylation in chondrocytes after stimulation with COMP and TSP-4. Chondrocytes were stimulated with $10 \mu \mathrm{g} / \mathrm{mL}$ COMP or TSP-4. Cell extracts were harvested and Smad as well as Erk proteins detected by immunoblot. (a) Representative immunoblots showing the detection of pErk1/2 and total Erk1/2. (b) Representative immunoblots showing the detection of $\mathrm{pSmad} 1 / 5 / 9$, Smad1/5/9, $\mathrm{pSmad} 2$ and Smad2. GAPDH was used as a loading control; $(n=4)$.

(a)

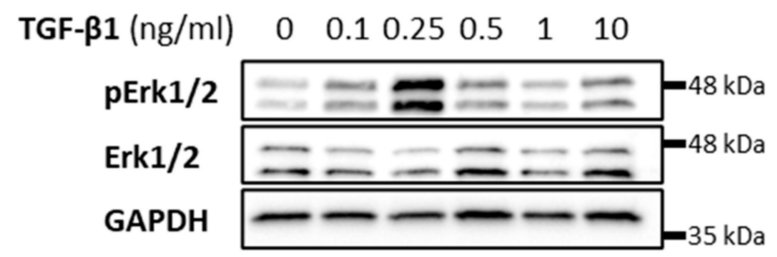

(b)

(c)

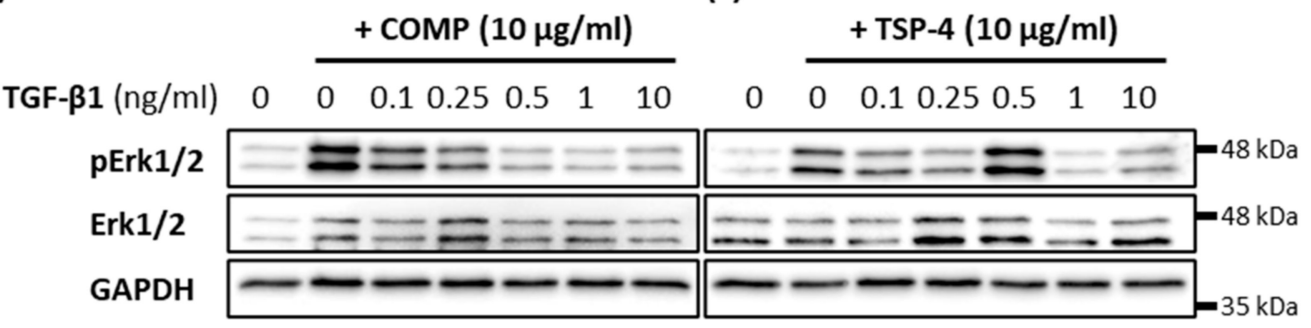

Figure 6. Modulation of TGF- $\beta 1$-induced Erk signaling in chondrocytes. Chondrocytes were stimulated with indicated concentrations of TGF- $\beta 1$ alone or in combination with COMP $(10 \mu \mathrm{g} / \mathrm{mL})$ or TSP-4 $(10 \mu \mathrm{g} / \mathrm{mL})$ before Erk $1 / 2$ proteins were detected by immunoblot. (a) Representative immunoblots show the concentration-dependent TGF- $\beta 1$ induced phosphorylation of Erk1/2 (pErk1/2) and total Erk1/2. Representative immunoblots show the influence of COMP (b) and TSP-4 (c) on the concentration-dependent TGF- $\beta 1$ induction of Erk1/2 phosphorylation. GAPDH was used as a loading control; $(n=4)$. 


\section{Discussion}

In the present study, we show that the presence and distribution of COMP and TSP-4 are distinguishable, especially in healthy and OA cartilage, although both proteins are re-expressed during OA progression. While COMP is ubiquitously expressed in healthy cartilage, TSP-4 is hardly detectable. In OA, COMP was found to be degraded in early and re-expressed in late-stage OA [15]. In contrast, the TSP-4 level dramatically increased in an early OA stage, and was shown to be further elevated with OA severity [39]. This differential expression pattern indicates additive roles of extracellular COMP and TSP-4 in articular cartilage that may depend on their zonal distribution.

In the past, it was shown that cells in the injured articular cartilage have the potential to migrate to the damage site, leading to a repopulation of these areas [48,49]. COMP re-expression was mainly found in the upper cartilage zones, where the structural damage was most severe, while TSP- 4 was predominantly expressed in the middle and deep zone, below the layer where COMP re-expression was detected. Therefore, we hypothesized that the re-expression of COMP might be an attempt to attract chondrocytes from the surrounding area to repopulate the defect site, and that interaction with COMP and TSP-4 might induce mechanisms of ECM maintenance, protection and cartilage repair. Indeed, COMP, but not TSP-4, was demonstrated to attract chondrocytes and contribute to their anchorage $[50,51]$. These data suggest that COMP and TSP-4 interact with differential receptors on the chondrocyte surface and are distinguishable in their functional role. Although the presence of TSP-4 is insignificant for chondrocyte migration, its rapid upregulation in injury is associated with the regulation of matrix protein synthesis and ECM remodeling [52-54]; both processes are highly relevant in OA. Also, induction of ECM protein synthesis seems highly likely and beneficial for COMP after mediating chondrocyte migration and attachment.

The effects of COMP-TGF- $\beta 1$ and TSP-4-TGF- $\beta 1$ complexes were also investigated, due to the important role of TGF- $\beta 1$ in healthy cartilage, its high abundance in OA and its susceptibility to modulation by COMP after binding [23,33,47]. In our study, we showed, for the first time, that not only COMP, but also TSP-4 directly interacts with TGF- $\beta 1$ (Appendix A), although TGF- $\beta 1$ only induced the expression of COMP and not TSP-4 (Appendix B). These findings, together with the low expression of TSP-4 under healthy conditions, suggest a minor role in the maintenance of healthy cartilage. In addition to TGF- $\beta 1$, COMP synthesis can be increased by mechanical loading, as shown in cartilage explants $[55,56]$. In the presence of cartilage lesions, the loading environment changes; this may lead to an altered response of chondrocytes, which deform less axially but are exposed to increased tensile strength compared to cells in an intact matrix [57,58]. Therefore, an altered loading environment in articular cartilage might also affect the expression of TSP-4 and further increase the levels of COMP. At the cellular level, we could show that both COMP and TSP-4 supported the synthesis and matrix deposition of collagen II, IX, XII and proteoglycans, while inhibiting those of collagen I and collagen X. The modulating effect of COMP has also been described before, showing that the addition of COMP or aggrecan suppresses the expression of hypertrophic genes in periosteal chondrocytes [59]. The increased expression of the main ECM components, collagen II and proteoglycans, as well as their potential to enhance TGF- $\beta 1$ induced collagen II and proteoglycan synthesis, strongly suggest an involvement of both proteins in cartilage repair by restoring an ECM composition that maintains original tensile strength and elasticity [1]. Collagen fibrils in articular cartilage consist mainly of collagen II [4], and their zonal specific biomechanical, as well as structural properties are achieved by its interaction with different ECM components such as collagen IX [4-6], resulting in a heterogeneity of collagen II cartilage fibrils [6-8]. Therefore, the effect of COMP and TSP-4 on the expression of minor collagens, like collagen IX and XII, is also of great interest. While COMP and TSP-4 can both bind fibrillar collagens [40-42], they behave differently in terms of their capacity to bind minor collagens. In that manner, COMP was shown to interact with collagen IX $[60,61]$ and collagen XII [43], while TSP-4 cannot directly bind to collagen IX [62], and the binding to 
collagen XII has not yet been investigated. Collagen XII, TSP-4 and COMP are all localized in the superficial zone in healthy cartilage, which possesses properties, such as high tensile strength to withstand the immense forces of articulation [5,8]. COMP and TSP-4 induce the synthesis of collagen XII, and may therefore increase the tensile properties in the superficial zone and prepare the underlaying tissue for increased loading. Especially in OA, affecting all cartilage layers, increased collagen XII levels may enhance the integrity of the ECM by strengthening collagen II fibrils. However, in combination with TGF- $\beta 1$, this increase seems reversed, maybe due to a negative feedback loop. TGF- $\beta 1$ stimulation resulted in high levels of immobilized and soluble collagen XII. These levels were much higher than those seen in COMP and TSP-4 stimulated cells. Downregulation of collagen XII might be a consequence of the binding of TGF- $\beta 1$ to COMP and TSP-4, blocking relevant binding sites, e.g., on growth factor receptors, as reported for a COMP-BMP-2 complex [63]. Conspicuously, collagen XII amounts were low in conditions where collagen IX was enriched. Also, collagen IX-KO mice showed an increased amount of collagen XII distributed in areas where collagen XII is usually not expressed [62]. Both FACIT collagens share sequence homologies and are associated with collagen organization [64], indicating a compensatory role of collagen XII in the absence of collagen IX. While collagen IX is rather associated with thinner collagen fibrils, lacking decorin [4,6,7], collagen XII is a known interaction partner, suggesting the involvement in the organization of collagen fibrils with larger diameter [65] and the tensile strength of articular cartilage. COMP and TSP-4 stimulation had different effects on collagen IX expression, which was upregulated by both proteins. However, increased amounts of soluble collagen IX were only detected in the supernatant of COMP stimulated cells, indicating an impaired matrix integration, maybe due to missing binding sites. Alternatively, the increased amounts of collagen IX could form complexes with COMP in the supernatant. COMP can directly bind to collagen IX with its C-terminal domain [60], suggesting a higher affinity of collagen IX to COMP than to other binding partners in the matrix. Collagen IX is entirely integrated into the cell-associated matrix when stimulated with TSP-4. The reason for this might, therefore, be a lower expression capacity or the different binding properties to collagen IX in comparison to COMP [62], excluding the possibility of a complex formation. Furthermore, the stimulation with COMP and TSP-4 resulted in a partially reduced amount of collagen I, and led to a shift in direction collagen II positive cells. Several studies have reported that prolonged culture of chondrocytes in monolayer lead to dedifferentiation, characterized by an increase of collagen I expression and, at the same time, a loss of cartilage-specific markers, like collagen II, collagen IX and, in particular, COMP $[35,66]$. Therefore, it is tempting to speculate that stimulation with COMP would counteract this dedifferentiation process. Indeed, our observations seem to confirm this hypothesis of chondrocyte phenotype stabilization after stimulation with COMP and also TSP-4, though to a lesser extent. However, the loss of collagen IX, visible in TGF- $\beta 1$ stimulated cultures, could not be reversed by a simultaneous treatment with COMP or TSP-4, demonstrating a dominant effect of TGF- $\beta 1$ on collagen IX expression and eventually also on the chondrocyte phenotype. A beneficial effect of COMP in cartilage regeneration was demonstrated by Wang C, et al. [67], showing that an overexpression of COMP promoted chondrogenic differentiation of bone-marrow derived stem cells, resulting in an increased formation of articular cartilage. Therefore, COMP and TSP-4 might be promising factors for clinical applications, e.g., in maintaining the chondrocyte phenotype during in vitro expansion for autologous chondrocyte implantation (ACI) or incorporated into scaffolds, improving cell anchorage, protecting chondrocytes phenotype and inducing the production of proteins, essential for ECM properties. 
After having demonstrated potential functional roles of COMP and TSP-4 in articular cartilage, we aimed to gain more insight into the involved signaling pathways. Chondrocytes in mature cartilage facilitate the maintenance of the ECM in a low turnover state [17], which requires a delicate balance of catabolic and anabolic processes, which are regulated by, among other mechanisms, growth factors like TGF- $\beta 1$ [23-26]. The most relevant pathways to maintain cartilage homeostasis are the Smad (small mothers against decapentaplegic homologs) and Erk1/2 signaling [26]. The counteracting Smad2/3 and Smad1/5/9 have different Smad-binding motifs in the DNA sequence, resulting in the downstream transcription of differential genes [26,68]. TGF- $\beta 1$ typically induce Smad2/3 signaling, promoting matrix maintenance by inhibiting chondrocyte hypertrophy $[29,30]$ and inducing the expression of matrix proteins like aggrecan and collagen II [24], similar to Erk1/2 [24,32]. Smad1/5/9 phosphorylation results in the opposite, i.e., the expression of collagen $X$ and MMP-13, causing chondrocyte hypertrophy and matrix degradation [31]. In $\mathrm{OA}$, reactivated chondrocytes fail to regulate the metabolism properly, leading to an imbalance of anabolic and catabolic processes. For presently unknown reasons, chondrocytes favor Smad1/5/9 and switch from an anabolic to a catabolic Erk1/2 signaling, in $\mathrm{OA}$, leading to an unstable chondrocyte phenotype and ECM degradation [69-71]. The capacity of COMP and TSP-4 to induce the Erk1/2 signaling pathway has already been demonstrated in other cell types, including primary hepatic stellate cells [72] and cardiomyocytes [73], respectively. Thereby, the Erk phosphorylation could be induced via the CD36 receptor [72], a receptor naturally expressed on healthy chondrocytes and even increasing in the pathology of OA [74]. In our study, we showed that COMP and TSP-4 could also induce the phosphorylation of Erk1/2 in articular chondrocytes, while none of the proteins had an effect on Smad1/5/9 or Smad2/3 signaling. Interestingly, it has been shown earlier that other ECM components, like e.g. collagen II, were able to suppress hypertrophy in articular chondrocytes via the Erk1/2 signaling pathway [32]. The similar effects of COMP and TSP-4 on protein synthesis and cell-signaling indicate that the upregulation of proteoglycan and collagen II, as well as the downregulation of collagen $X$, might be mediated via Erk1/2 signaling, while migration is most likely performed by an Erk1/2-independent mechanism. Nonetheless, future studies are necessary to confirm the role of Erk1/2, as well as to identify the responsible receptors.

The present study was limited by the availability of healthy human articular cartilage samples. The distribution and expression of COMP and TSP-4 was investigated in human osteoarthritic and healthy cartilage samples. Thereby, we could show that the ECM composition had already been altered in an early OA stage (G1), i.e., at which obvious morphological defects were not yet detectable. Therefore, healthy pig cartilage was used to study the effects of COMP and TSP-4 on chondrocytes in vitro. The effect of COMP and TSP-4 on OA chondrocytes has to be investigated in more detail in future experiments.

In summary, these data demonstrate that chondrocytes in articular cartilage can activate mechanisms to protect and repair the ECM in injury and disease. COMP and TSP-4, distributed in different cartilage zones, might contribute to the integrity and repair of the ECM by promoting chondrocyte migration and ECM protein synthesis, as well as the stabilization of the chondrocyte phenotype (Figure 7). Their involvement in direct and indirect cell signaling emphasizes the complexity of cell-matrix interactions and intracellular events in degenerative processes. Overall, OA leads to cartilage degradation, despite the protective effects of COMP and TSP-4. However, these repair processes might help to slow the progression of OA, and thus pave the way for new treatment strategies. 


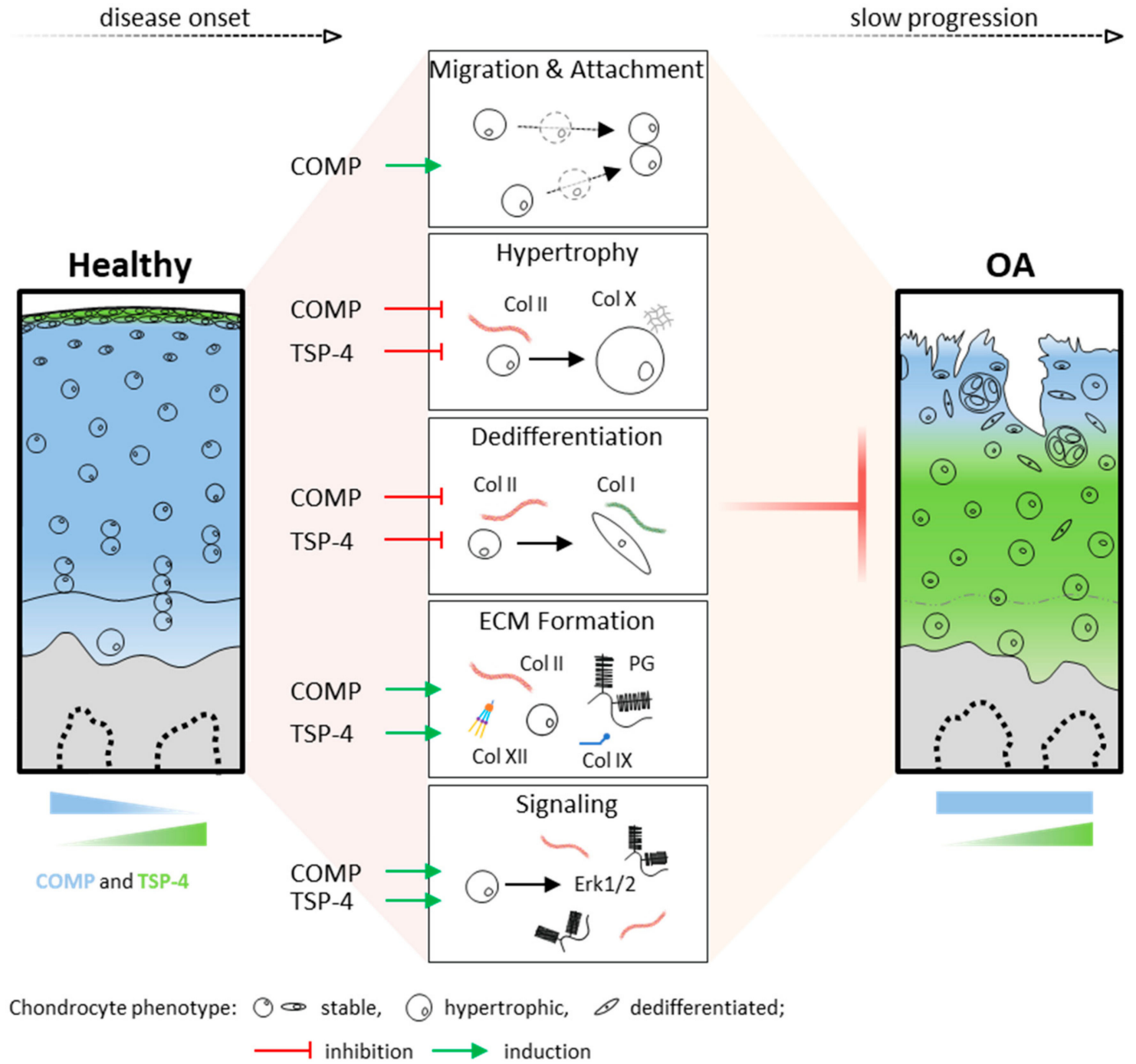

Figure 7. Functional role and distribution of COMP and TSP-4 in articular cartilage. Schematic representation of COMP and TSP-4 distribution, as well as protein levels in healthy and OA cartilage. Areas of COMP and TSP-4 expression are indicated in blue and green, respectively. Their impact on cartilage and OA relevant processes is depicted in the middle. Green arrows indicate an induction, while red T arrows mean inhibition. PG = proteoglycan and Col = collagen.

\section{Materials and Methods}

\subsection{Collection and Scoring of Human Osteochondral Cylinders}

Adult, human, anonymized cartilage samples were obtained from seven OA patients undergoing endoprosthetic knee replacement surgery at the Department of Orthopaedics (Friedrichsheim), University Hospital Frankfurt, Goethe University, and visually scored as described before [39]. Intact cartilage areas with a smooth and shiny surface were scored as grade 1 (G1), cartilage areas with superficial fissures and a rough surface were scored as grade 2, and areas with deeper fissures and/or exposure of subchondral bone as grade 3 to 4 (G3/4). Two non-OA cartilage sections staining were a gift from Gerjo van Osch (Erasmus MC University Rotterdam, Rotterdam, The Netherlands) and used as healthy controls. 


\subsection{Chondrocyte Isolation and Culture from Pig Articular Cartilage}

Pig legs were obtained from the animal house at Goethe University Frankfurt, Frankfurt/Main, Germany from among animals sacrificed within the scope of other scientific projects. Legs from female, healthy pigs (three to six months old) were received immediately after sacrificing. Pig legs were processed to expose the knee and the knee joint was opened to scrape off the articular cartilage from the femoral condyles under sterile conditions. The cartilage was washed with phosphate-buffered saline (PBS; Thermo Fisher Scientific, Waltham, MA, USA) and cut into small pieces $\left(2-3 \mathrm{~mm}^{3}\right)$ to isolate chondrocytes. The cartilage pieces of pig knee joints were weighted, transferred into a sterile tube and digested with $0.2 \%$ pronase (Roche Diagnostics, Mannheim, Germany) in DMEM/F12 medium containing 5\% FBS and 5\% pen/strep (all from Gibco, Karlsruhe, Germany) for $2 \mathrm{~h}$ at $37^{\circ} \mathrm{C}$ with the agitation of $60 \mathrm{rpm}$. After incubation, cells and cartilage pieces were pelleted by centrifugation at $300 \times g, 5 \mathrm{~min}$ at RT and the supernatant decanted. Cells and cartilage pieces were washed $3 \times$ with PBS and digested with $200 \mathrm{U} / \mathrm{mL}$ collagenase type II (Biochrom, Berlin, Germany) solution in DMEM/F12 medium (containing 5\% FBS and 5\% pen/strep) overnight at $37^{\circ} \mathrm{C}$ with the agitation of $60 \mathrm{rpm}$. The chondrocyte suspension was filtered through a $70 \mu \mathrm{m}$ nylon cell strainer and centrifuged at $300 \mathrm{xg}$ for $5 \mathrm{~min}$ at RT. The pelleted cells were resuspended, counted with a Neubauer chamber and seeded either in DMEM/F12 containing 5\% FBS or resuspended in medium containing $0.1 \%$ bovine serum albumin (BSA; PanReac, AppliChem, Darmstadt, Gemany) for direct use in the migration assay. All cells were cultured at $37^{\circ} \mathrm{C}, 5 \% \mathrm{CO}_{2}$ and $20 \% \mathrm{O}_{2}$ in a $\mathrm{CO}_{2}$-incubator.

To analyze the production of matrix proteins and matrix formation via immunofluorescence staining and immunoblot analysis, 40,000 cells in DMEM/F12 containing 5\% FBS were seeded in each chamber of a Nunc ${ }^{\mathrm{TM}} \mathrm{Lab}^{-\mathrm{Tek}^{\mathrm{TM}}}{ }^{\mathrm{II}}$ four-well chamber slide (Thermo Fisher Scientific, Waltham, MA, USA). Chondrocytes used for signaling experiments were seeded in a density of 300,000 cells in DMEM/F12 containing 5\% FBS per well of a six-well plate. The cells were allowed to attach to the bottom overnight. The following day, the cells were washed twice with PBS and starved in basic medium (DMEM/F12 containing $0.1 \% \mathrm{BSA}$ and $25 \mu \mathrm{g} / \mathrm{mL}$ ascorbic acid (Sigma-Aldrich, St. Louis, MO, USA)) for $24 \mathrm{~h}$. Then, the cells were stimulated with recombinant proteins. Different concentrations of TGF- $\beta 1$ (R\&D Systems, Minneapolis, MN, USA) were used, depending on the downstream assay. In all assays, recombinantly expressed and purified COMP and TSP-4 were used in a concentration of $10 \mu \mathrm{g} / \mathrm{mL}$. The chondrocytes were treated with TGF- $\beta 1$, COMP or TSP-4 alone and in the combination of TGF- $\beta 1$ with COMP or TSP- 4 in basic medium. When cells were stimulated in the combination of TGF- $\beta 1$ with COMP or TSP-4, the two components were mixed in a tube and pre-incubated for $20 \mathrm{~min}$ at RT, before applying to the cells.

Chondrocytes seeded in chamber slides were stimulated with $0.5 \mathrm{ng} / \mathrm{mL}$ TGF- $\beta 1$, $10 \mu \mathrm{g} / \mathrm{mL}$ COMP, $10 \mu \mathrm{g} / \mathrm{mL}$ TSP- 4 and in the combination of TGF- $\beta 1$ with COMP or TSP-4 for a period of seven days. The chondrocytes were first stimulated with recombinant protein in the basic medium for four days. The medium was changed at day 4 and recombinant proteins applied in a basic medium containing 5\% FBS. At day 7, the medium was replaced by a basic medium containing only $5 \%$ FBS and chondrocytes cultured until day 10 . The supernatants were collected after each medium change and stored at $-20^{\circ} \mathrm{C}$.

For immunoblot analyses, chondrocytes were stimulated with $0.1 \mathrm{ng} / \mathrm{mL}, 0.25 \mathrm{ng} / \mathrm{mL}$, $0.5 \mathrm{ng} / \mathrm{mL}, 1 \mathrm{ng} / \mathrm{mL}$ and $10 \mathrm{ng} / \mathrm{mL}$ TGF- $\beta 1,10 \mu \mathrm{g} / \mathrm{mL}$ COMP, $10 \mu \mathrm{g} / \mathrm{mL}$ TSP 4 or a combination of all TGF- $\beta 1$ concentrations with COMP or TSP-4 for 30 min at $37^{\circ} \mathrm{C}$.

\subsection{Expression and Purification of Recombinant Proteins}

Recombinant TSP-4 and COMP were produced as described before [75,76]. Shortly, HEK-293 EBNA cells were transfected with the pCEP-Pu V162 expression vector (generated by Prof. Manuel Koch, University of Cologne) carrying the sequence of full-length rat COMP and TSP-4 and cultured in DMEM/F12 medium containing 1\% FBS for a period of five days. The cell culture supernatant was collected daily and cleared by centrifugation. The recombinant proteins were purified via the Strep-Tag affinity chromatography column 
(IBA, Goettingen, Germany) at day five. The protein concentration was measured with the Qubit fluorometer and protein fractions stored at $-20^{\circ} \mathrm{C}$ until use.

\section{4. (Immuno)histological and Immunofluorescence Staining of Cartilage Samples and Chondrocytes}

Osteochondral cylinders were generated and processed as described before [39]. Samples were fixed in $4 \%$ paraformaldehyde (Sigma-Aldrich, St. Louis, MO, USA) in PBS, $\mathrm{pH}=7.4$, overnight at $4{ }^{\circ} \mathrm{C}$. After decalcification in $10 \%$ ethylenediaminetetraacetic acid (EDTA; VWR, Osterode am Harz, Germany), samples were embedded in paraffin. Then, $5 \mu \mathrm{m}$ sections were generated, deparaffinized and rehydrated prior to antigen retrieval. Tissue sections were treated with $250 \mathrm{U}$ hyaluronidase (Sigma-Aldrich) in PBS (pH = 5) before TSP-4 staining and with $20 \mu \mathrm{g} / \mathrm{mL}$ proteinase K (Qiagen, Hilden, Germany) in proteinase $\mathrm{K}$ buffer $\left(10 \mathrm{mM} \mathrm{NaCl}, 50 \mathrm{mM}\right.$ Tris-base, $10 \mathrm{mM}$ EDTA in $\mathrm{ddH}_{2} \mathrm{O}$, pH 7.4) before COMP staining, for $15 \mathrm{~min}$ at $37^{\circ} \mathrm{C}$. Endogenous peroxidase activity was blocked with $0.3 \%$ $\mathrm{H}_{2} \mathrm{O}_{2}$ (Carl Roth, Karlsruhe, Germany) in $\mathrm{dH}_{2} \mathrm{O}$ for $10 \mathrm{~min}$ at RT and unspecific binding blocked with $2.5 \%$ normal horse serum (included in the ImmPRESS ${ }^{\mathrm{TM}}$ HRP reagent kit, Vector Laboratories, Burlingame, CA, USA) for $20 \mathrm{~min}$ at RT. Primary antibodies (Table 1) were diluted in $1 \%$ BSA and the tissue sections incubated at $4{ }^{\circ} \mathrm{C}$ overnight. The primary antibodies were detected with the ImmPRESS ${ }^{\mathrm{TM}}$ (peroxidase) polymer anti-rabbit IgG reagent (included in the ImmPRESS ${ }^{\mathrm{TM}}$ HRP Reagent Kit, Vector Laboratories, Burlingame, CA, USA) at RT for 30 min. The AEC-2-component kit (DCS, Hamburg, Germany) was used according to the manufacturer's instructions to visualize the secondary antibody. Negative control staining without addition of the primary antibodies were carried out to exclude unspecific binding of the secondary antibody (data not shown).

Table 1. List of primary antibodies.

\begin{tabular}{|c|c|c|c|}
\hline Target & Host & Dilution & Source or Supplier \\
\hline Collagen I & rabbit & 1:200 (IF), 1:1000 (IB) & Abcam (ab34710) \\
\hline Collagen II & mouse & 1:200 (IF), 1:1000 (IB) & Merck (CP18) \\
\hline Collagen IX & guinea pig & 1:200 (IF), 1:1000 (IB) & {$[77]$} \\
\hline Collagen $X$ & mouse & 1:50 (IF), 1:100 (IB) & Mengjie Zhou (University of Cologne) \\
\hline Collagen XII & rabbit & $1: 200(\mathrm{IF}), 1: 1000(\mathrm{IB})$ & Manuel Koch (University of Cologne) \\
\hline COMP & rabbit & 1:100 (IF), 1:500 (IHC), 1:1000 (IB) & {$[78]$} \\
\hline TSP-4 & rabbit & 1:100 (IF), 1:500 (IHC) & [39] \\
\hline TSP-4 & guinea pig & $1: 1000(\mathrm{IB})$ & {$[40,79]$} \\
\hline Smad2 & rabbit & $1: 1000$ (IB) & Cell Signaling (5339) \\
\hline pSmad2 & rabbit & 1:2000 (IB) & Cell Signaling (3108) \\
\hline Smad1/5/9 & rabbit & 1:500 (IB) & Santa Cruz (sc-6031-R) \\
\hline $\mathrm{pSmad} 1 / 5 / 9$ & rabbit & 1:1000 (IB) & Cell Signaling (13820) \\
\hline Erk1/2 & mouse & $1: 2500$ (IB) & Cell Signaling (9107) \\
\hline pErk1/2 & rabbit & 1:2000 (IB) & Cell Signaling (4370) \\
\hline GAPDH & mouse & 1:2000 (IB) & Thermo Fisher Scientific (MA5-15738) \\
\hline
\end{tabular}

Cultured chondrocytes in chamber slides were fixed with Shandon ${ }^{\mathrm{TM}}$ zinc formalfixx $^{\mathrm{TM}}$ (Thermo Fisher Scientific, Waltham, MA, USA) for $20 \mathrm{~min}$ at RT, washed 3x with PBS. To stain proteoglycans cells were incubated with $0.1 \%$ Safranin-O (Carl Roth, Karlsruhe, Germany) at RT for $15 \mathrm{~min}$. Before antibody staining, cells were permeabilized with $0.3 \%$ Triton X-100 (Merck, Darmstadt, Germany) in PBS for 10 min at RT. Unspecific binding sites were blocked with blocking buffer (1\% BSA and 1\% goat serum (Abcam, Cambridge, UK) in PBS) for $1 \mathrm{~h}$ at RT. Cells were incubated with the primary antibodies (Table 1) diluted in $1 \%$ BSA in PBS at $4{ }^{\circ} \mathrm{C}$ overnight. After three washing steps with PBS-T (PBS containing 0.1\% Tween-20 (Carl Roth, Karlsruhe, Germany)), cells were incubated with the corresponding secondary antibodies (Table 2) diluted in 1\% BSA in PBS at RT in the dark for $1.5 \mathrm{~h}$. The cells were washed twice with PBS-T and once with PBS before mounting with the DAPI fluoroshield mounting medium (Abcam, Cambridge, UK). DAPI was visualized 
at a wavelength of $461 \mathrm{~nm}$, Alexa Fluor 488 at $516 \mathrm{~nm}$ and Alexa Fluor 594 at $617 \mathrm{~nm}$ with a fluorescence and Safranin-O with a light microscope (Nikon, Tokyo, Japan).

Table 2. List of conjugated antibodies.

\begin{tabular}{ccccc}
\hline Target & Host & Conjugated & Dilution & Reference or Producer \\
\hline Rabbit IgG & goat & HRP & $1: 1000(\mathrm{IB}, \mathrm{IHC})$ & Agilent (P0448) \\
Guinea pig IgG & rabbit & HRP & $1: 1000(\mathrm{IB}, \mathrm{IHC})$ & Agilent (P014102-2) \\
Mouse IgG & goat & HRP & $1: 1000(\mathrm{IB}, \mathrm{IHC})$ & Agilent (P0447) \\
Rabbit IgG & goat & Alexa Fluor 594 & $1: 500(\mathrm{IF})$ & Invitrogen (A-11037) \\
Guinea pig IgG & goat & Alexa Fluor 488 & $1: 500(\mathrm{IF})$ & Invitrogen (A-11073) \\
Mouse IgG & goat & Alexa Fluor 488 & $1: 500(\mathrm{IF})$ & Invitrogen (A-11029) \\
\hline
\end{tabular}

\subsection{Protein Extraction and Analysis}

Proteins from human cartilage samples were extracted as described previously [39]. Briefly, cartilage from areas showing different severity grades were scraped off and cut into pieces $\left(1-3 \mathrm{~mm}^{3}\right)$, and proteins were extracted with an extraction buffer (4 M guanidine hydrochloride, $50 \mathrm{mM}$ Tris, $10 \mathrm{mM}$ EDTA $(\mathrm{pH}=7.4)$ ) overnight at $4{ }^{\circ} \mathrm{C}$. After precipitating the proteins with $96 \%$ ethanol for $24 \mathrm{~h}$ at $-20^{\circ} \mathrm{C}$, the protein pellet was washed and resuspended in Laemmli buffer ( $250 \mathrm{mM}$ Tris- $\mathrm{HCl}, \mathrm{pH} 6.8,40 \%$ glycerol, $0.04 \%$ bromophenol blue, $8 \%$ SDS).

Cells in monolayer culture were washed with PBS and cell lysates collected by scraping the cells in 1x Laemmli buffer containing 40\% $\beta$-mercaptoethanol (Sigma-Aldrich, St. Louis, MO, USA) and phosphoSafe ${ }^{\mathrm{TM}}$ (Merck, Darmstadt, Germany). Cell culture supernatants were mixed with Laemmli buffer with or without $\beta$-mercaptoethanol.

For quantification, proteins were separated by SDS-PAGE using $5 \%, 8 \%$ or $10 \%$ polyacrylamide gels as previously described [39]. The separation was carried out using a Mini-PROTEAN ${ }^{\circledR}$ Tetra-cell system (Bio-Rad, Munich, Germany) at $150 \mathrm{~V}$ and equal loading was demonstrated by PageBlue ${ }^{\mathrm{TM}}$ (Thermo Fisher Scientific, Waltham, MA, USA) or Roti ${ }^{\circledR}$ blue (Carl Roth, Karlsruhe, Germany) staining of total proteins. After electrophoresis, proteins were transferred onto a $0.45 \mu \mathrm{m}$ polyvinylidene fluoride (PVDF) membrane (GE Healthcare, Freiburg, Germany) using the mini Trans-blot ${ }^{\circledR}$ electrophoretic transfer cell (Bio-Rad, Munich, Germany) and unspecific binding sites blocked in 10\% skim milk (COMP and TSP-4) or 5\% BSA (signaling proteins and collagens) at RT for $1 \mathrm{~h}$ with gentle agitation. Membranes were incubated with the corresponding antibodies listed in Table 1 at $4{ }^{\circ} \mathrm{C}$ overnight. After washing, membranes were incubated with the corresponding secondary antibodies (Table 2) for $1 \mathrm{~h}$ at RT and the proteins visualized by using a mixture of a homemade ECL solution (0.1 M Tris- $\mathrm{HCl}, \mathrm{pH}=8.5 ; 225 \mathrm{mM} p$-coumaric acid and $1.25 \mathrm{mM}$ luminol) with $3 \% \mathrm{H}_{2} \mathrm{O}_{2}$. The protein signals were analyzed by the Chemi Doc $^{\mathrm{TM}}$ XRS+ (Bio-Rad, Munich, Germany) molecular imager and the ImageLab ${ }^{\mathrm{TM}}$ software (http:/ / www.bio-rad.com/de-de/product/image-lab-software) (accessed on 1 January 2021). The band intensities were quantified with the ImageJ version 1.5 software (http://imagej.nih.gov/ij) (accessed on 1 January 2021).

\subsection{Migration Assay}

The transwell system with ThinCert ${ }^{\mathrm{TM}}$ cell culture inserts containing a polyethylene terephthalate (PET) membrane with a pore size of $8 \mu \mathrm{m}$ was used in combination with 24-well plates to investigate the migration of primary pig chondrocytes. First, $400 \mu \mathrm{L}$ DMEM/F12 containing $0.1 \%$ BSA with either $10 \mu \mathrm{g} / \mathrm{mL}$ COMP or $10 \mu \mathrm{g} / \mathrm{mL}$ TSP-4 were added to the lower compartment of the transwell system. As a positive control, chondrocytes were attracted with $10 \mathrm{ng} / \mathrm{mL}$ platelet-derived growth factor-BB (PDGF-BB) (Miltenyi Biotec, Bergisch Gladbach, Germany). As a negative control, the plenty medium was added in the lower compartment. Chondrocytes were directly used after isolation from knee cartilage and washed twice with PBS before use in migration assays. Then, 50,000 cells in $200 \mu \mathrm{L}$ medium were transferred to the upper compartment of the inserts. After $10 \mathrm{~h}$ 
incubation at $37{ }^{\circ} \mathrm{C}, 5 \% \mathrm{CO}_{2}$ and $20 \% \mathrm{O}_{2}$, the cells within and on the lower side of the PET membrane were fixed with Shandon ${ }^{\mathrm{TM}}$ zinc formal-fixx $^{\mathrm{TM}}$ for $20 \mathrm{~min}$ at RT. Nonmigrated chondrocytes on the upper side of the PET membrane were removed using a cotton swab. After a brief rinse in $\mathrm{dH}_{2} \mathrm{O}$, the nuclei were stained with DAPI (Sigma-Aldrich, St. Louis, $\mathrm{MO}, \mathrm{USA}$ ) and imaged with a fluorescent microscope at a wavelength of $461 \mathrm{~nm}$. Five pictures from different areas of the membrane were taken and the number of cells counted with ImageJ. The fold change of the number of cells which had migrated toward COMP, TSP-4 and the positive control were calculated based on the number of cells which had migrated toward the negative control. All technical replicates were performed at least in duplicate.

\subsection{Attachememt Assay}

Wells of a 96-well plate were coated with $10 \mu \mathrm{g} / \mathrm{mL}$ COMP and TSP-4 in PBS. As a negative control $100 \mathrm{mg} / \mathrm{mL}$ BSA and as a positive control $10 \mu \mathrm{g} / \mathrm{mL}$ fibronectin (R\&D Systems, Minneapolis, MN, USA), were used. The recombinant protein, in the indicated concentration, were added to each well and incubated overnight at $4{ }^{\circ} \mathrm{C}$. The following day, the wells were washed twice for $5 \mathrm{~min}$ with PBS and once for $5 \mathrm{~min}$ with DMEM/F12 containing $0.1 \%$ BSA. After blocking with $1 \%$ BSA for $3 \mathrm{~h}$ at RT, chondrocytes were added at a concentration of 50,000 cells in DMEM/F12 containing 0.1\% BSA. Chondrocytes were incubated for $1 \mathrm{~h}$ at $37{ }^{\circ} \mathrm{C}$ and $5 \% \mathrm{CO}_{2}$ in a $\mathrm{CO}_{2}$-incubator. Following the incubation, the supernatant was carefully removed and the wells briefly washed twice with PBS. Chondrocytes were fixed with Shandon ${ }^{\mathrm{TM}}$ zinc formal-fixx ${ }^{\mathrm{TM}}$ for $20 \mathrm{~min}$ at RT. Cells were washed three times for 5 min each with PBS and stained with $0.1 \%$ crystal-violet for $30 \mathrm{~min}$ at RT. The cells were washed three times for 5 min each with $\mathrm{ddH}_{2} \mathrm{O}$ and imaged with a light microscope. The number of cells was counted and the fold change to the negative control calculated. All technical replicates were performed in triplicates.

\subsection{Surface Plasmon Resonance Spectroscopy}

The interaction between proteins was measured with the Biacore 2000 (Biacore AB, Uppsala, Sweden). All experiments were performed at $25^{\circ} \mathrm{C}$ and with a $\mathrm{CM} 5$ sensor chip coupled with 1500 U TGF- $\beta 1$. As a reference, a flow cell without an immobilized ligand was used. A 1:2 dilution series from a concentration of $160 \mathrm{~nm}$ to $0 \mathrm{~nm}$ of the analytes, COMP and TSP-4, were prepared in a running buffer (Biacore AB, Uppsala, Sweden). The system was equilibrated at a flow rate of $30 \mu \mathrm{l} / \mathrm{min}$ with the running buffer, and the experiment started when a stable baseline was reached. The injection of the analyte was started and data were collected for kinetic analysis. One analyte concentration per cycle was injected, starting with the lowest concentration. The chip was regenerated after each cycle with $2 \mathrm{M} \mathrm{NaCl}$.

The BIAevaluation software 3.0 (Biacore AB, Uppsala, Sweden) was used to create a sensorgram, showing the response against the time. By doing a multicycle kinetic, several analyte concentrations were induced in separate cycles, resulting in multiple curves in the sensorgram. By fitting the curves to the mathematical 1:1 model, the association rate (ka), dissociation rate $(\mathrm{kd})$ and the dissociation constant $\left(\mathrm{K}_{\mathrm{d}}\right)$ was evaluated.

\subsection{Statistical Analysis}

The SigmaPlot version 13.0 software (Systat Software, Inc., San Jose, CN, USA) was used for statistical analyses. Differences between groups were evaluated by the paired $t$-test, One Way ANOVA or the Friedman test with either the Tukey, Student-NewmanKeuls Method or Dunnett's post hoc test. Correlations between groups were analyzed by using the Spearman rank test (r). A $p$-value $<0.05$ was considered as significant difference $\left(p<0.05^{*} ; p \leq 0.01^{* *} ; p \leq 0.001^{* * *}\right)$. 
Author Contributions: Conceptualization, K.M. and F.Z.; methodology, K.M. and F.Z.; validation, K.M. and F.Z.; formal data analysis, K.M., E.A.S., E.F., A.M. and F.Z.; investigation, K.M. and E.A.S.; resources, F.Z.; writing—original draft preparation, K.M. and F.Z.; writing—review and editing, K.M., E.A.S., E.F., A.M. and F.Z.; visualization, K.M.; funding acquisition, F.Z. All authors have read and agreed to the published version of the manuscript.

Funding: This project has received funding from the European Union's Horizon 2020 research and innovation program under Marie Sklodowska-Curie grant agreement No 721432 (to K.M., E.A.S., E.F. and F.Z.). Parts of this work were funded by the German Research Foundation through RU2722, project number 407168728 (to F.Z.).

Institutional Review Board Statement: This study was reviewed and approved by the Ethical Committee of the Medical Faculty at the Goethe University in Frankfurt, Germany. The tissue that was used would have been discarded after knee replacement surgery. As all samples were anonymized and no patient-related data were collected a more detailed review was not needed.

Informed Consent Statement: Patient consent was waived by the local ethical committee due to fact that the samples were anonymized and could not be tracked back to the individual donor.

Data Availability Statement: The data presented in this study are available on request from the corresponding author.

Conflicts of Interest: The authors declare no conflict of interest.

\begin{tabular}{ll} 
Abbreviations \\
BMP & Bone morphogenetic protein \\
BSA & Bovine serum albumin \\
Col & Collagen \\
COMP & Cartilage oligomeric matrix protein \\
DAPI & $4^{\prime}$,6-diamidino-2-phenylindole \\
DMEM & Dulbecco's Modified Eagle's Medium \\
EBNA & Epstein-Barr virus nuclear antigen \\
ECM & Extracellular matrix \\
EDTA & Ethylenediaminetetraacetic acid \\
Erk & Extracellular-signal regulated kinases \\
EtOH & Ethanol \\
F & Fraction \\
FACIT & Fibril-associated collagens with interrupted triple helices \\
FBS & Fetal bovine serum \\
G & Grade \\
GAPDH & Glycerinaldehyd-3-phosphat-dehydrogenase \\
HC & Healthy control \\
HEK cells & Human embryonic kidney cells \\
HRP & Horseradish peroxidase \\
IB & Immunoblot \\
IF & Immunofluorescence \\
IHC & Immunohistochemistry \\
ka & Association rate \\
kd & Dissociation rate \\
$k_{D}$ & Dissociation constant \\
kDa & Kilo Dalton \\
LC & Loading control \\
OA & Osteoarthritis \\
PBS & Phosphate-buffered saline \\
PDGF & Platelet-derived growth factor \\
Pen/strep & Penicillin/streptomycin \\
PET & Polyethylene terephthalate \\
& \\
\hline
\end{tabular}




$\begin{array}{ll}\text { PG } & \text { Proteoglycan } \\ \text { PVDF } & \text { Polyvinylidene fluoride } \\ \text { Rec } & \text { Recombinant } \\ \text { rpm } & \text { Revolutions per minute } \\ \text { RT } & \text { Room temperature } \\ \text { RU } & \text { Response Units } \\ \text { SDS-PAGE } & \text { Sodium dodecyl sulfate polyacrylamide gel electrophoresis } \\ \text { Smad } & \text { Small mothers against decapentaplegic homologs } \\ \text { TGF- } \beta 1 & \text { Transforming growth factor-beta 1 } \\ \text { TSP-4 } & \text { Thrombospondin-4 }\end{array}$

\section{Appendix A. Both, COMP and TSP-4 Interact with TGF- $\beta 1$}

COMP and TSP-4 had similar capacities to contribute to the ECM formation and could further modulate TGF- $\beta 1$ induced Erk1/2 signaling. A direct interaction of COMP with TGF- $\beta 1$ has been described earlier. This interaction was shown to modulate the bioactivity of TGF- $\beta 1$ [47]. However, it was unclear if TSP-4 also directly interacts with TGF- $\beta 1$. Therefore, the interaction of both proteins with TGF- $\beta 1$ was characterized in surface plasmon resonance measurements using the Biacore system. The protein-protein interaction profiles show that both COMP (Figure A1a) and TSP-4 (Figure A1b) interact with TGF- $\beta 1$. According to the calculated $K_{d}$ value, the affinity of TSP- 4 for TGF- $\beta 1$ seems to be slightly stronger than that of COMP. However, due to the low dissociation rate of COMP, a direct comparison is difficult (Figure A1c).

(a)

COMP (0-160nM)

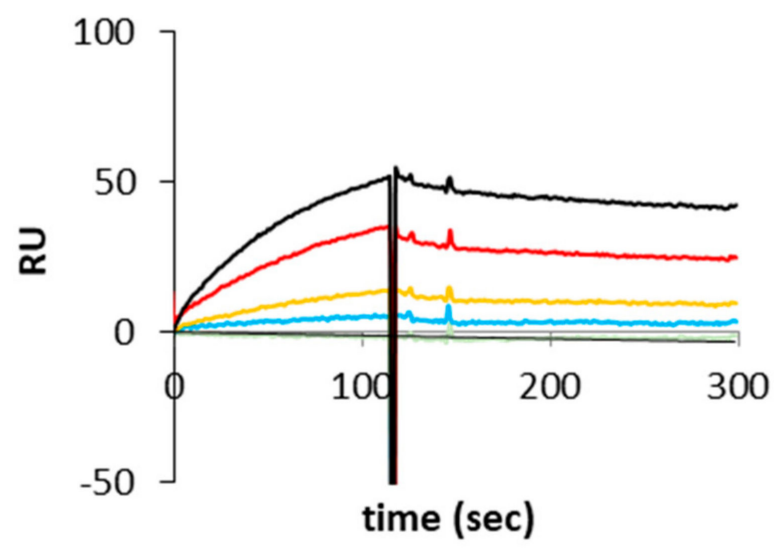

(b)

TSP-4 (0-160nM)

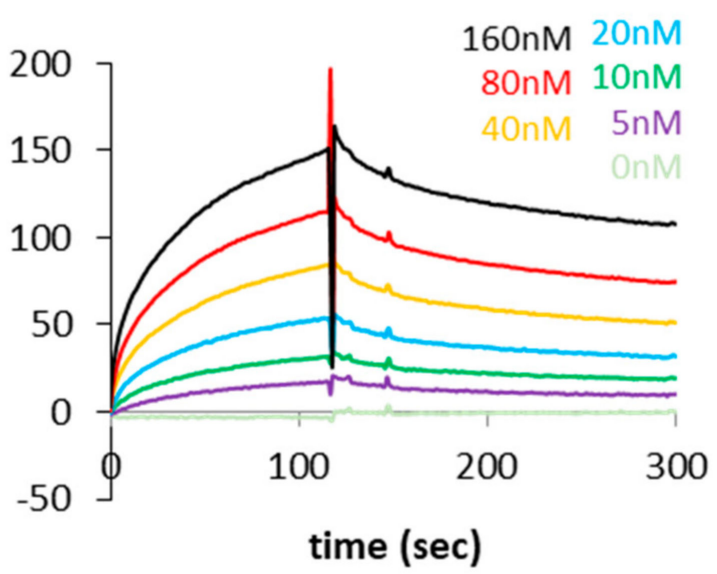

(c)

\begin{tabular}{c|c|c|c|c|c|c} 
Ligand & Analyte & Model & $\mathbf{C h i}^{2}$ & $\mathbf{k a ~ ( 1 / M s )}$ & $\mathbf{k d ~ ( 1 / s )}$ & $\mathbf{K}_{\mathbf{d}}$ (nM) \\
\hline TGF- $\beta 1$ & COMP & $1: 1$ & 4.6 & $1.71^{-4}$ & $3.92^{-4}$ & 22.9 \\
TGF- $\beta 1$ & TSP-4 & $1: 1$ & 10.3 & $1.41^{-5}$ & $8.89^{-4}$ & 6.30
\end{tabular}

Figure A1. Surface plasmon resonance measurements show a direct interaction of COMP and TSP- 4 with TGF- $\beta 1$. Proteinprotein interaction profiles showing the binding of COMP and TSP-4 to TGF- $\beta 1$. Surface plasmon resonance sensorgrams generated with the Biacore system are shown for COMP (a) and TSP-4 (b). Resonance signals expressed as response units (RU), indicate the degree of binding COMP and TSP-4 with TGF- $\beta 1$. COMP and TSP-4 were used in concentrations ranging from 5 to $160 \mathrm{nM}$ and injected to immobilized TGF- $\beta 1$ on a CM5 chip. (c) Summary of the data received from Biacore assays. The association rate $(\mathrm{ka})$, the dissociation rate $(\mathrm{kd})$, the dissociation constant $\left(\mathrm{K}_{\mathrm{d}}\right)$ and the chi ${ }^{2}$ are represented. A kinetic $1: 1$ model (Langmuir model) was used to calculate these parameters. 


\begin{abstract}
Appendix B. TGF-B1 Promotes the Synthesis and Deposition of COMP but Not TSP-4
Previously, it was shown that COMP and TSP- 4 could directly bind to TGF- $\beta 1$ and modulate its bioactivity. Further, Motaung SC, et al. [80] showed that TGF- $\beta 1$ could also induce the synthesis of COMP. To investigate if also TSP- 4 is induced after TGF- $\beta 1$ treatment, primary chondrocytes were stimulated with $0.5 \mathrm{ng} / \mathrm{mL}$ TGF- $\beta 1$ for seven days in monolayer culture and the matrix deposition of COMP and TSP-4 stained with specific antibodies at day 10 . TGF- $\beta 1$ could induce the synthesis and matrix deposition of COMP but not TSP-4 (Figure A2a). Soluble COMP could be detected in the supernatant of controls and to a larger extend in the supernatant of TGF- $\beta 1$ stimulated cells, although in none of the cultures soluble TSP-4 could be detected (Figure A2b).
\end{abstract}

(a)

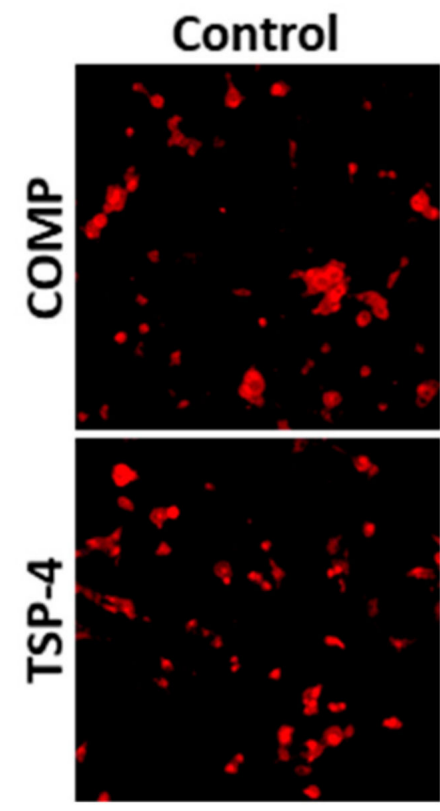

(b)

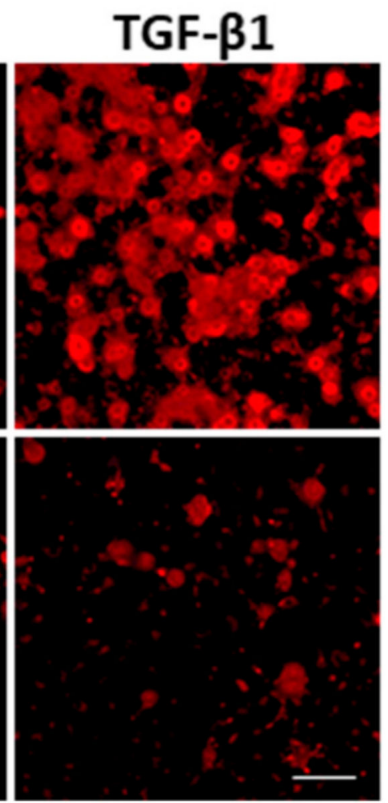

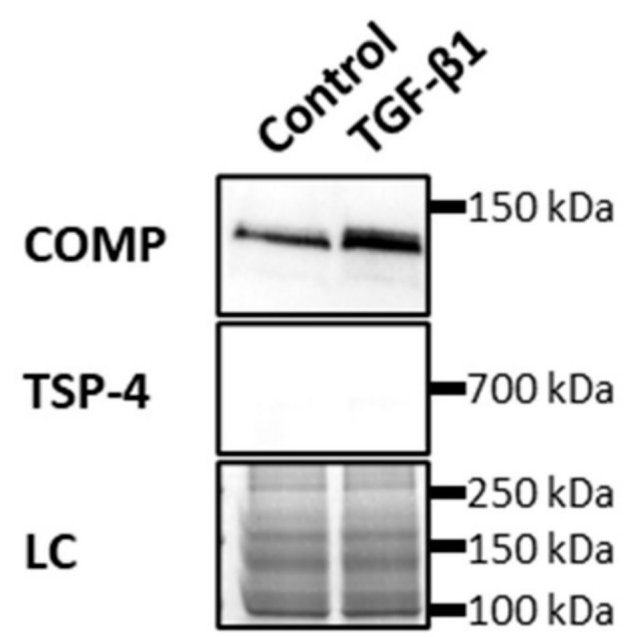

Figure A2. The effect of TGF- $\beta 1$ on COMP and TSP-4 synthesis and deposition. Chondrocytes were stimulated with TGF- $\beta 1$ $(0.5 \mathrm{ng} / \mathrm{mL})$ for seven days. COMP and TSP-4 were detected with specific antibodies. (a) Immunofluorescence staining of COMP and TSP-4 at day 10. (b) Immunoblot assays of chondrocyte supernatants at day 10. Roti ${ }^{\circledR}$ blue staining of proteins was used as a loading control (LC). ( $n=3$ per group); unstimulated cells were used as a control; scale bar $=100 \mu \mathrm{m}$.

\title{
References
}

1. Sophia Fox, A.J.; Bedi, A.; Rodeo, S.A. The basic science of articular cartilage: Structure, composition, and function. Sports Health 2009, 1, 461-468. [CrossRef] [PubMed]

2. Bhosale, A.M.; Richardson, J.B. Articular cartilage: Structure, injuries and review of management. Br. Med. Bull. 2008, 87, 77-95. [CrossRef]

3. Athanasiou, K.A.; Darling, E.M.; Hu, J.C.; DuRaine, G.D.; Reddi, A.H. Articular Cartilage; CRC Press: Boca Raton, FL, USA, 2013.

4. Eyre, D.R. Collagens and cartilage matrix homeostasis. Clin. Orthop. Relat. Res. 2004, S118-S122. [CrossRef]

5. Kempson, G.E.; Freeman, M.A.; Swanson, S.A. Tensile properties of articular cartilage. Nature 1968, 220, 1127-1128. [CrossRef] [PubMed]

6. Gottardi, R.; Hansen, U.; Raiteri, R.; Loparic, M.; Düggelin, M.; Mathys, D.; Friederich, N.F.; Bruckner, P.; Stolz, M. Supramolecular Organization of Collagen Fibrils in Healthy and Osteoarthritic Human Knee and Hip Joint Cartilage. PLoS ONE 2016, 11, e0163552. [CrossRef]

7. Hagg, R.; Bruckner, P.; Hedbom, E. Cartilage fibrils of mammals are biochemically heterogeneous: Differential distribution of decorin and collagen IX. J. Cell Biol. 1998, 142, 285-294. [CrossRef]

8. Gregory, K.E.; Keene, D.R.; Tufa, S.F.; Lunstrum, G.P.; Morris, N.P. Developmental distribution of collagen type XII in cartilage: Association with articular cartilage and the growth plate. J. Bone Miner. Res. 2001, 16, 2005-2016. [CrossRef] 
9. Yamagata, M.; Yamada, K.M.; Yamada, S.S.; Shinomura, T.; Tanaka, H.; Nishida, Y.; Obara, M.; Kimata, K. The complete primary structure of type XII collagen shows a chimeric molecule with reiterated fibronectin type III motifs, von Willebrand factor A motifs, a domain homologous to a noncollagenous region of type IX collagen, and short collagenous domains with an Arg-Gly-Asp site. J. Cell Biol. 1991, 115, 209-221. [CrossRef]

10. Eyre, D.R.; Weis, M.A.; Wu, J.J. Articular cartilage collagen: An irreplaceable framework? Eur. Cells Mater. 2006, 12, 57-63. [CrossRef] [PubMed]

11. Luckman, S.P.; Rees, E.; Kwan, A.P. Partial characterization of cell-type X collagen interactions. Biochem. J. 2003, 372, 485-493. [CrossRef]

12. Aspden, R.M. Fibre reinforcing by collagen in cartilage and soft connective tissues. Proc. Biol. Sci. 1994, 258, 195-200. [CrossRef] [PubMed]

13. Gibson, G.J.; Bearman, C.H.; Flint, M.H. The immunoperoxidase localization of type X collagen in chick cartilage and lung. Collagen Relat. Res. 1986, 6, 163-184. [CrossRef]

14. Bonen, D.K.; Schmid, T.M. Elevated extracellular calcium concentrations induce type X collagen synthesis in chondrocyte cultures. J. Cell Biol. 1991, 115, 1171-1178. [CrossRef] [PubMed]

15. Koelling, S.; Clauditz, T.S.; Kaste, M.; Miosge, N. Cartilage oligomeric matrix protein is involved in human limb development and in the pathogenesis of osteoarthritis. Arthritis Res. Ther. 2006, 8, R56. [CrossRef] [PubMed]

16. Halász, K.; Kassner, A.; Mörgelin, M.; Heinegård, D. COMP acts as a catalyst in collagen fibrillogenesis. J. Biol. Chem. 2007, 282, 31166-31173. [CrossRef]

17. Goldring, M.B. Chondrogenesis, chondrocyte differentiation, and articular cartilage metabolism in health and osteoarthritis. Ther. Adv. Musculoskelet. Dis. 2012, 4, 269-285. [CrossRef]

18. Loeser, R.F.; Goldring, S.R.; Scanzello, C.R.; Goldring, M.B. Osteoarthritis: A disease of the joint as an organ. Arthritis Rheum. 2012, 64, 1697-1707. [CrossRef]

19. Neogi, T. The epidemiology and impact of pain in osteoarthritis. Osteoarthr. Cartil. 2013, 21, 1145-1153. [CrossRef]

20. Sofat, N. Analysing the role of endogenous matrix molecules in the development of osteoarthritis. Int. J. Exp. Pathol. 2009, 90, 463-479. [CrossRef]

21. Grimmer, C.; Balbus, N.; Lang, U.; Aigner, T.; Cramer, T.; Müller, L.; Swoboda, B.; Pfander, D. Regulation of type II collagen synthesis during osteoarthritis by prolyl-4-hydroxylases: Possible influence of low oxygen levels. Am. J. Pathol. 2006, 169, 491-502. [CrossRef]

22. Lippiello, L.; Hall, D.; Mankin, H.J. Collagen synthesis in normal and osteoarthritic human cartilage. J. Clin. Investig. 1977, 59, 593-600. [CrossRef]

23. Grimaud, E.; Heymann, D.; Rédini, F. Recent advances in TGF-beta effects on chondrocyte metabolism. Potential therapeutic roles of TGF-beta in cartilage disorders. Cytokine Growth Factor Rev. 2002, 13, 241-257. [CrossRef]

24. Zhu, Y.; Tao, H.; Jin, C.; Liu, Y.; Lu, X.; Hu, X.; Wang, X. Transforming growth factor- $\beta 1$ induces type II collagen and aggrecan expression via activation of extracellular signal-regulated kinase $1 / 2$ and Smad2/3 signaling pathways. Mol. Med. Rep. 2015, 12, 5573-5579. [CrossRef] [PubMed]

25. Recklies, A.D.; Baillargeon, L.; White, C. Regulation of cartilage oligomeric matrix protein synthesis in human synovial cells and articular chondrocytes. Arthritis Rheum. 1998, 41, 997-1006. [CrossRef]

26. Thielen, N.G.; van der Kraan, P.M.; van Caam, A.P. TGF $\beta /$ BMP Signaling Pathway in Cartilage Homeostasis. Cells 2019,8 , 969. [CrossRef]

27. Fortier, L.A.; Barker, J.U.; Strauss, E.J.; McCarrel, T.M.; Cole, B.J. The role of growth factors in cartilage repair. Clin. Orthop. Relat. Res. 2011, 469, 2706-2715. [CrossRef]

28. Gao, Y.; Liu, S.; Huang, J.; Guo, W.; Chen, J.; Zhang, L.; Zhao, B.; Peng, J.; Wang, A.; Wang, Y.; et al. The ECM-cell interaction of cartilage extracellular matrix on chondrocytes. BioMed Res. Int. 2014, 2014, 648459. [CrossRef]

29. Kim, K.-O.; Sampson, E.R.; Maynard, R.D.; O’Keefe, R.J.; Chen, D.; Drissi, H.; Rosier, R.N.; Hilton, M.J.; Zuscik, M.J. Ski inhibits TGF- $\beta$ /phospho-Smad3 signaling and accelerates hypertrophic differentiation in chondrocytes. J. Cell. Biochem. 2012, 113, 2156-2166. [CrossRef]

30. Ferguson, C.M.; Schwarz, E.M.; Reynolds, P.R.; Puzas, J.E.; Rosier, R.N.; O'Keefe, R.J. Smad2 and 3 mediate transforming growth factor- $\beta 1$-induced inhibition of chondrocyte maturation. Endocrinology 2000, 141, 4728-4735. [CrossRef] [PubMed]

31. Blaney Davidson, E.N.; Remst, D.F.; Vitters, E.L.; van Beuningen, H.M.; Blom, A.B.; Goumans, M.J.; van den Berg, W.B.; van der Kraan, P.M. Increase in ALK1/ALK5 ratio as a cause for elevated MMP-13 expression in osteoarthritis in humans and mice. J. Immunol. 2009, 182, 7937-7945. [CrossRef] [PubMed]

32. Lian, C.; Wang, X.; Qiu, X.; Wu, Z.; Gao, B.; Liu, L.; Liang, G.; Zhou, H.; Yang, X.; Peng, Y.; et al. Collagen type II suppresses articular chondrocyte hypertrophy and osteoarthritis progression by promoting integrin $\beta 1-S M A D 1$ interaction. Bone Res. 2019, 7, 8. [CrossRef]

33. Fava, R.; Olsen, N.; Keski-Oja, J.; Moses, H.; Pincus, T. Active and latent forms of transforming growth factor beta activity in synovial effusions. J. Exp. Med. 1989, 169, 291-296. [CrossRef] [PubMed]

34. Hall, A.C. The Role of Chondrocyte Morphology and Volume in Controlling Phenotype-Implications for Osteoarthritis, Cartilage Repair, and Cartilage Engineering. Curr. Rheumatol. Rep. 2019, 21, 38. [CrossRef] 
35. Zaucke, F.; Dinser, R.; Maurer, P.; Paulsson, M. Cartilage oligomeric matrix protein (COMP) and collagen IX are sensitive markers for the differentiation state of articular primary chondrocytes. Biochem. J. 2001, 358, 17-24. [CrossRef] [PubMed]

36. Miosge, N.; Hartmann, M.; Maelicke, C.; Herken, R. Expression of collagen type I and type II in consecutive stages of human osteoarthritis. Histochem. Cell Biol. 2004, 122, 229-236. [CrossRef] [PubMed]

37. Kirsch, T.; Swoboda, B.; Nah, H. Activation of annexin II and V expression, terminal differentiation, mineralization and apoptosis in human osteoarthritic cartilage. Osteoarthr. Cartil. 2000, 8, 294-302. [CrossRef]

38. Von der Mark, K.; Frischholz, S.; Aigner, T.; Beier, F.; Belke, J.; Erdmann, S.; Burkhardt, H. Upregulation of type X collagen expression in osteoarthritic cartilage. Acta Orthop. Scand. Suppl. 1995, 266, 125-129. [CrossRef]

39. Maly, K.; Schaible, I.; Riegger, J.; Brenner, R.E.; Meurer, A.; Zaucke, F. The Expression of Thrombospondin-4 Correlates with Disease Severity in Osteoarthritic Knee Cartilage. Int. J. Mol. Sci. 2019, 20, 447. [CrossRef]

40. Narouz-Ott, L.; Maurer, P.; Nitsche, D.P.; Smyth, N.; Paulsson, M. Thrombospondin-4 binds specifically to both collagenous and non-collagenous extracellular matrix proteins via its C-terminal domains. J. Biol. Chem. 2000, 275, 37110-37117. [CrossRef] [PubMed]

41. Gebauer, J.M.; Köhler, A.; Dietmar, H.; Gompert, M.; Neundorf, I.; Zaucke, F.; Koch, M.; Baumann, U. COMP and TSP-4 interact specifically with the novel GXKGHR motif only found in fibrillar collagens. Sci. Rep. 2018, 8, 17187. [CrossRef] [PubMed]

42. Rosenberg, K.; Olsson, H.; Mörgelin, M.; Heinegård, D. Cartilage oligomeric matrix protein shows high affinity zinc-dependent interaction with triple helical collagen. J. Biol. Chem. 1998, 273, 20397-20403. [CrossRef]

43. Agarwal, P.; Zwolanek, D.; Keene, D.R.; Schulz, J.N.; Blumbach, K.; Heinegård, D.; Zaucke, F.; Paulsson, M.; Krieg, T.; Koch, M.; et al. Collagen XII and XIV, new partners of cartilage oligomeric matrix protein in the skin extracellular matrix suprastructure. J. Biol. Chem. 2012, 287, 22549-22559. [CrossRef] [PubMed]

44. Di Cesare, P.E.; Chen, F.S.; Moergelin, M.; Carlson, C.S.; Leslie, M.P.; Perris, R.; Fang, C. Matrix-matrix interaction of cartilage oligomeric matrix protein and fibronectin. Matrix Biol. 2002, 21, 461-470. [CrossRef]

45. Mann, H.H.; Özbek, S.; Engel, J.; Paulsson, M.; Wagener, R. Interactions between the cartilage oligomeric matrix protein and matrilins Implications for matrix assembly and the pathogenesis of chondrodysplasias. J. Biol. Chem. 2004, 279, 25294-25298. [CrossRef] [PubMed]

46. Tan, K.; Lawler, J. The interaction of Thrombospondins with extracellular matrix proteins. J. Cell Commun. Signal. 2009, 3, 177-187. [CrossRef]

47. Haudenschild, D.R.; Hong, E.; Yik, J.H.; Chromy, B.; Mörgelin, M.; Snow, K.D.; Acharya, C.; Takada, Y.; Di Cesare, P.E. Enhanced activity of transforming growth factor $\beta 1$ (TGF- $\beta 1$ ) bound to cartilage oligomeric matrix protein. J. Biol. Chem. 2011, 286, 43250-43258. [CrossRef]

48. Koelling, S.; Kruegel, J.; Irmer, M.; Path, J.R.; Sadowski, B.; Miro, X.; Miosge, N. Migratory chondrogenic progenitor cells from repair tissue during the later stages of human osteoarthritis. Cell Stem Cell 2009, 4, 324-335. [CrossRef]

49. Seol, D.; McCabe, D.J.; Choe, H.; Zheng, H.; Yu, Y.; Jang, K.; Walter, M.W.; Lehman, A.D.; Ding, L.; Buckwalter, J.A.; et al. Chondrogenic progenitor cells respond to cartilage injury. Arthritis Rheum. 2012, 64, 3626-3637. [CrossRef] [PubMed]

50. Jeschke, A.; Bonitz, M.; Simon, M.; Peters, S.; Baum, W.; Schett, G.; Ruether, W.; Niemeier, A.; Schinke, T.; Amling, M. Deficiency of Thrombospondin-4 in Mice Does Not Affect Skeletal Growth or Bone Mass Acquisition, but Causes a Transient Reduction of Articular Cartilage Thickness. PLoS ONE 2015, 10, e0144272. [CrossRef]

51. Chen, F.H.; Thomas, A.O.; Hecht, J.T.; Goldring, M.B.; Lawler, J. Cartilage oligomeric matrix protein/thrombospondin 5 supports chondrocyte attachment through interaction with integrins. J. Biol. Chem. 2005, 280, 32655-32661. [CrossRef]

52. Frolova, E.G.; Sopko, N.; Blech, L.; Popovic, Z.B.; Li, J.; Vasanji, A.; Drumm, C.; Krukovets, I.; Jain, M.K.; Penn, M.S.; et al. Thrombospondin-4 regulates fibrosis and remodeling of the myocardium in response to pressure overload. FASEB J. 2012, 26, 2363-2373. [CrossRef]

53. Mustonen, E.; Aro, J.; Puhakka, J.; Ilves, M.; Soini, Y.; Leskinen, H.; Ruskoaho, H.; Rysä, J. Thrombospondin-4 expression is rapidly upregulated by cardiac overload. Biochem. Biophys. Res. Commun. 2008, 373, 186-191. [CrossRef] [PubMed]

54. Subramanian, A.; Schilling, T.F. Thrombospondin-4 controls matrix assembly during development and repair of myotendinous junctions. eLife 2014, 3, e02372. [CrossRef]

55. Giannoni, P.; Siegrist, M.; Hunziker, E.B.; Wong, M. The mechanosensitivity of cartilage oligomeric matrix protein (COMP). Biorheology 2003, 40, 101-109.

56. Wong, M.; Siegrist, M.; Cao, X. Cyclic compression of articular cartilage explants is associated with progressive consolidation and altered expression pattern of extracellular matrix proteins. Matrix Biol. 1999, 18, 391-399. [CrossRef]

57. Gratz, K.R.; Wong, B.L.; Bae, W.C.; Sah, R.L. The effects of focal articular defects on cartilage contact mechanics. J. Orthop. Res. 2009, 27, 584-592. [CrossRef]

58. Moo, E.K.; Han, S.K.; Federico, S.; Sibole, S.C.; Jinha, A.; Abu Osman, N.A.; Pingguan-Murphy, B.; Herzog, W. Extracellular matrix integrity affects the mechanical behaviour of in-situ chondrocytes under compression. J. Biomech. 2014, 47, 1004-1013. [CrossRef] [PubMed]

59. Caron, M.M.; Janssen, M.P.; Peeters, L.; Haudenschild, D.R.; Cremers, A.; Surtel, D.A.; van Rhijn, L.W.; Emans, P.J.; Welting, T.J. Aggrecan and COMP improve periosteal chondrogenesis by delaying chondrocyte hypertrophic maturation. Front. Bioeng. Biotechnol. 2020, 8, 1036. [CrossRef] 
60. Holden, P.; Meadows, R.S.; Chapman, K.L.; Grant, M.E.; Kadler, K.E.; Briggs, M.D. Cartilage oligomeric matrix protein interacts with type IX collagen, and disruptions to these interactions identify a pathogenetic mechanism in a bone dysplasia family. J. Biol. Chem. 2001, 276, 6046-6055. [CrossRef] [PubMed]

61. Thur, J.; Rosenberg, K.; Nitsche, D.P.; Pihlajamaa, T.; Ala-Kokko, L.; Heinegård, D.; Paulsson, M.; Maurer, P. Mutations in cartilage oligomeric matrix protein causing pseudoachondroplasia and multiple epiphyseal dysplasia affect binding of calcium and collagen I, II, and IX. J. Biol. Chem. 2001, 276, 6083-6092. [CrossRef] [PubMed]

62. Brachvogel, B.; Zaucke, F.; Dave, K.; Norris, E.L.; Stermann, J.; Dayakli, M.; Koch, M.; Gorman, J.J.; Bateman, J.F.; Wilson, R. Comparative proteomic analysis of normal and collagen IX null mouse cartilage reveals altered extracellular matrix composition and novel components of the collagen IX interactome. J. Biol. Chem. 2013, 288, 13481-13492. [CrossRef]

63. Du, Y.; Wang, Y.; Wang, L.; Liu, B.; Tian, Q.; Liu, C.J.; Zhang, T.; Xu, Q.; Zhu, Y.; Ake, O.; et al. Cartilage oligomeric matrix protein inhibits vascular smooth muscle calcification by interacting with bone morphogenetic protein-2. Circ. Res. 2011, 108, 917-928. [CrossRef]

64. Gordon, M.K.; Gerecke, D.R.; Dublet, B.; van der Rest, M.; Olsen, B.R. Type XII collagen. A large multidomain molecule with partial homology to type IX collagen. J. Biol. Chem. 1989, 264, 19772-19778. [CrossRef]

65. Font, B.; Eichenberger, D.; Rosenberg, L.M.; van der Rest, M. Characterization of the interactions of type XII collagen with two small proteoglycans from fetal bovine tendon, decorin and fibromodulin. Matrix Biol. 1996, 15, 341-348. [CrossRef]

66. Darling, E.M.; Pritchett, P.E.; Evans, B.A.; Superfine, R.; Zauscher, S.; Guilak, F. Mechanical properties and gene expression of chondrocytes on micropatterned substrates following dedifferentiation in monolayer. Cell. Mol. Bioeng. 2009, 2, 395-404. [CrossRef] [PubMed]

67. Wang, C.; Liu, G.; Zhang, W.; Wang, W.; Ma, C.; Liu, S.; Fan, C.; Liu, X. Cartilage oligomeric matrix protein improves in vivo cartilage regeneration and compression modulus by enhancing matrix assembly and synthesis. Colloids Surf. B Biointerfaces 2017, 159, 518-526. [CrossRef]

68. Zawel, L.; Dai, J.L.; Buckhaults, P.; Zhou, S.; Kinzler, K.W.; Vogelstein, B.; Kern, S.E. Human Smad3 and Smad4 are sequencespecific transcription activators. Mol. Cell 1998, 1, 611-617. [CrossRef]

69. Van der Kraan, P.M.; Goumans, M.J.; Blaney Davidson, E.; ten Dijke, P. Age-dependent alteration of TGF- $\beta$ signalling in osteoarthritis. Cell Tissue Res. 2012, 347, 257-265. [CrossRef]

70. Xia, M.; Zhu, Y. Fibronectin fragment activation of ERK increasing integrin $\alpha_{5}$ and $\beta_{1}$ subunit expression to degenerate nucleus pulposus cells. J. Orthop. Res. 2011, 29, 556-561. [CrossRef] [PubMed]

71. Daheshia, M.; Yao, J.Q. The interleukin 1beta pathway in the pathogenesis of osteoarthritis. J. Rheumatol. 2008, 35, 2306-2312 [CrossRef]

72. Magdaleno, F.; Arriazu, E.; de Galarreta, M.R.; Chen, Y.; Ge, X.; de la Rosa, L.C.; Nieto, N. Cartilage oligomeric matrix protein participates in the pathogenesis of liver fibrosis. J. Hepatol. 2016, 65, 963-971. [CrossRef] [PubMed]

73. Cingolani, O.H.; Kirk, J.A.; Seo, K.; Koitabashi, N.; Lee, D.I.; Ramirez-Correa, G.; Bedja, D.; Barth, A.S.; Moens, A.L.; Kass, D.A. Thrombospondin-4 is required for stretch-mediated contractility augmentation in cardiac muscle. Circ. Res. 2011, 109, 1410-1414. [CrossRef] [PubMed]

74. Pfander, D.; Cramer, T.; Deuerling, D.; Weseloh, G.; Swoboda, B. Expression of thrombospondin-1 and its receptor CD36 in human osteoarthritic cartilage. Ann. Rheum. Dis. 2000, 59, 448-454. [CrossRef]

75. Hansen, U.; Platz, N.; Becker, A.; Bruckner, P.; Paulsson, M.; Zaucke, F. A secreted variant of cartilage oligomeric matrix protein carrying a chondrodysplasia-causing mutation (p.H587R) disrupts collagen fibrillogenesis. Arthritis Rheum. 2011, 63, 159-167. [CrossRef]

76. Crosby, N.D.; Zaucke, F.; Kras, J.V.; Dong, L.; Luo, Z.D.; Winkelstein, B.A. Thrombospondin-4 and excitatory synaptogenesis promote spinal sensitization after painful mechanical joint injury. Exp. Neurol. 2015, 264, 111-120. [CrossRef]

77. Budde, B.; Blumbach, K.; Ylöstalo, J.; Zaucke, F.; Ehlen, H.W.; Wagener, R.; Ala-Kokko, L.; Paulsson, M.; Bruckner, P.; Grässel, S. Altered integration of matrilin-3 into cartilage extracellular matrix in the absence of collagen IX. Mol. Cell. Biol. 2005, 25, 10465-10478. [CrossRef] [PubMed]

78. DiCesare, P.E.; Mörgelin, M.; Mann, K.; Paulsson, M. Cartilage oligomeric matrix protein and thrombospondin 1. Purification from articular cartilage, electron microscopic structure, and chondrocyte binding. Eur. J. Biochem. 1994, 223, 927-937. [CrossRef] [PubMed]

79. Dunkle, E.T.; Zaucke, F.; Clegg, D.O. Thrombospondin-4 and matrix three-dimensionality in axon outgrowth and adhesion in the developing retina. Exp. Eye Res. 2007, 84, 707-717. [CrossRef]

80. Motaung, S.C.; Di Cesare, P.E.; Reddi, A.H. Differential response of cartilage oligomeric matrix protein (COMP) to morphogens of bone morphogenetic protein/transforming growth factor- $\beta$ family in the surface, middle and deep zones of articular cartilage. J. Tissue Eng. Regen. Med. 2011, 5, e87-e96. [CrossRef] [PubMed] 